\title{
Parameter estimation in a minimal model of cardio-pulmonary interactions
}

\author{
Sébastien de Bournonville ${ }^{\mathrm{a}, \mathrm{b}}{ }^{1}$, Antoine Pironet ${ }^{\mathrm{b}}$, Chris Pretty ${ }^{\mathrm{c}}$, J. Geoffrey \\ Chase ${ }^{\mathrm{c}}$, Thomas Desaive ${ }^{\mathrm{b}}$
}

${ }^{a}$ KU Leuven (KUL), Prometheus, Division of Skeletal Tissue Engineering, Leuven, Belgium.

b University of Liège (ULg), GIGA-In Silico Medicine, Liège, Belgium

${ }^{\mathrm{c}}$ University of Canterbury, Department of Mechanical Engineering, Christchurch, New Zealand

\begin{abstract}
Mechanical ventilation is a widely used breathing support for patients in intensive care. Its effects on the respiratory and cardiovascular systems are complex and difficult to predict. This work first presents a minimal mathematical model representing the mechanics of both systems and their interaction, in terms of flows, pressures and volumes. The aim of this model is to get insight on the two systems status when mechanical ventilation settings, such as positive end-expiratory pressure, are changing. The parameters of the model represent cardiac elastances and vessel compliances and resistances. As a second step, these parameters are estimated from 16 experimental datasets. The data come from three pig experiments reproducing intensive care conditions, where a large range of positive end-expiratory pressures was imposed by the mechanical ventilator. The data used for parameter estimation is limited to information available in the intensive care unit, such as stroke volume, central venous pressure and systemic arterial pressure. The model is able to satisfactorily reproduce this experimental data, with mean relative errors ranging from 1 to $26 \%$. The model also reproduces the dynamics of the cardio-vascular and respiratory systems, and their interaction. By looking at the estimated parameter values, one can quantitatively track how the two coupled systems mechanically react to changes in external conditions imposed by the ventilator. This work thus allows real-time, model-based management of ventilator settings.
\end{abstract}

\footnotetext{
${ }^{1}$ Corresponding author. E-mail addresses: sebadebour@gmail.com (Sébastien de Bournonville), a.pironet@alumni.ulg.ac.be (Antoine Pironet), chris.pretty@canterbury.ac.nz (Chris Pretty), geoff.chase@canterbury.ac.nz (J. Geoffrey Chase), tdesaive@ulg.ac.be (Thomas Desaive)
} 


\section{Keywords}

Cardio-pulmonary interactions; Cardiovascular system model; Respiratory system model; Mechanical ventilation; Intensive care unit; Parameter estimation

\section{Introduction}

In the intensive care unit (ICU), many patients are mechanically ventilated [1]. The positive end-expiratory pressure (PEEP) imposed by the ventilator is an important setting of mechanical ventilation, as it ensures that the lungs remain inflated at end-expiration [2], maintaining recruitment. However, an excessive PEEP can damage the lungs [2]. In addition, mechanical ventilation also affects the cardiovascular system (CVS) in many ways. These effects are complex and difficult to predict $[2,3]$.

Mathematical models are powerful tools to gain understanding of a systems inner working and to make predictions about its behaviour in different conditions. For a model to be a reliable tool, the unknown quantities it involves, called parameters, have to be estimated from the available experimental data. In the case of the CVS and respiratory systems, the parameters involved include cardiac elastance and vessel compliances and resistances [3-5]. Thus, by fitting a cardio-pulmonary model with patient data, the effects of mechanical ventilation on the structures of the CVS could become quantifiable, allowing real-time, model-based management of ventilator settings. Such work has never been performed.

To the best of the authors knowledge, only two studies have modelled the respiratory system and the CVS, and their interaction [6, 7]. However, parameter estimation was not performed in these two studies, meaning that these models were only qualitatively validated [8], and are not ready to be used as monitoring or prediction tools.

On the other hand, several models have previously been proposed to separately represent the CVS [3-5, 9-34] and the respiratory system [35-41]. Most of these models are lumped-parameter models, where the CVS or respiratory system is modelled as an interconnection of compartments, described with simple equations involving flows, pressures and volumes. Parameter estimation has been performed in many of these CVS [3-5, 9-18, 27-30] and respiratory system models [36, 37, 40], sometimes leading to structural and practical nonidentifiability issues $[4,8,13,15,37,40,42,43]$. Non-identifiability issues occur mainly when the number of parameters to estimate is too large with respect to the amount of data available, which is of particular concern in the ICU, where data is scarce [9].

This work first introduces a new, minimal cardio-respiratory model, formulated by merging an existing CVS model and a respiratory system model. The 
two separate models were both previously proven to be identifiable from ICU data, thus greatly reducing potential non-identifiability problems. With the aim of cardio-pulmonary monitoring in the ICU, the parameters of the cardiorespiratory model are then estimated using clinical hemodynamic data from porcine experiments reproducing ICU conditions, with a large range of ventilator settings. This work thus presents a first attempt at parameter estimation on a cardio-respiratory model using ICU data.

\section{Materials and methods}

The cardio-pulmonary coupling model presented in this work is an assembly of two models: a respiratory system model and a CVS model (Fig. 1). The respiratory system model is a single compartment model (Fig. 1, left). The CVS model is a three-chamber model of the systemic circulation (Fig. 1, right). They are linked by thoracic pressure, $P_{t h}$.

\subsection{Cardiovascular system model}

The three-chamber CVS model (Fig. 1) is a minimal model including the aorta (ao), one vena cava (vc) and left ventricle (lv) [13, 14]. This model was proven to be structurally [15] and practically [13] identifiable. Model chambers are joined by flow resistances representing the left ventricular valves and the systemic circulation.

The arterial and venous compartments are represented using purely passive chambers, where the pressure, $P_{i}$, is proportional to the volume, $V_{i}$ :

$$
P_{i}(t)=E_{i}\left(V_{i}(t)-V_{U, i}\right), \quad i=a o, v c
$$

where the parameters $E_{i}$ and $V_{U, i}$ are the elastance and the unstressed blood volume of the chamber $i$. The stressed blood volume is defined:

$$
V_{S, i}(t)=V_{i}(t)-V_{U, i} .
$$

Stressed volume, $V_{S, i}(t)$, of chamber $i$ corresponds to the amount of blood in the chamber that contributes to pressure changes. The pressure-volume relationships in the vena cava and aorta become, respectively:

$$
P_{v c}(t)=E_{v c} V_{S, v c}(t)+P_{t h}(t) \quad \text { and } \quad P_{a o}(t)=E_{a o} V_{S, a o}(t) .
$$

where the presence (or absence) of intra-thoracic pressure, $P_{t h}(t)$ is discussed in Section 2.3.

Similarly to [16], left ventricular pressure $P_{l v}(t)$ is the sum of a free wall ventricular pressure $P_{l v, f}(t)$ and the intrathoracic pressure $P_{t h}(t)$ acting on the ventricle:

$$
P_{l v}(t)=P_{l v, f}(t)+P_{t h}(t) .
$$




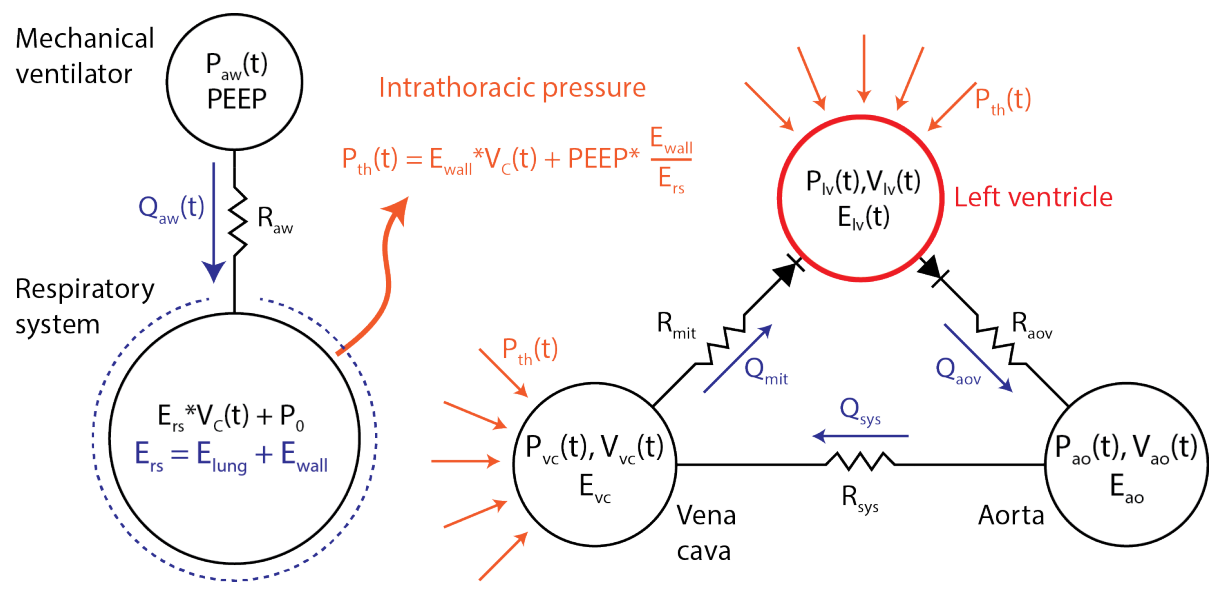

Figure 1: Electrical representation of the model. Left: simple lung model. Right: 3-chamber CVS model. Thoracic pressure, $P_{t h}$, links the models.

The active nature of the left ventricle is described using a time-varying pressurevolume relationship, defined [16]:

$$
P_{l v, f}(t)=e_{l v}(t) E_{l v, e s}\left(V_{l v}(t)-V_{l v, d}\right)+\left(1-e_{l v}(t)\right) E_{l v, e d}\left(V_{l v}(t)-V_{l v, u}\right),
$$

where $E_{l v, e s}$ and $E_{l v, e d}$ are respectively the end-systolic and end-diastolic elastances of the left ventricle. Equation 5 assumes linear end-systolic (ESPVR) [1618, 44] and end-diastolic [34] pressure-volume relationships.

The time-varying parameter $e_{l v}(t)$ in Equation 5 represents the normalised time-varying elastance of the left ventricle $[4,16]$ :

$$
e_{l v}(t)=\exp \left\{-W\left[(t \bmod T)-\frac{T}{2}\right]^{2}\right\}
$$

where $W$ dictates the width of the Gaussian function, mod denotes the modulo operator, and $T$ is the cardiac period. This driver function model is the simplest possible (cfr. Fig. 5), involving only two parameters, while others typically require more [11, 20-25].

The model chambers are linked by flow resistances representing the mitral valve (mit), the aortic valve (aov) and the systemic capillaries (sys). The systemic circulation flow, $Q_{\text {sys }}(t)$, is described using Poiseuille's equation:

$$
Q_{s y s}(t)=\frac{P_{a o}(t)-P_{v c}(t)}{R_{s y s}} .
$$

There is flow through a cardiac valve only if the pressure difference across the 
valve is positive:

$$
\begin{aligned}
& Q_{m i t}(t)=\left\{\begin{array}{lll}
\frac{P_{v c}(t)-P_{l v}(t)}{R_{m i t}} & \text { if } & P_{v c}(t)>P_{l v}(t) \\
0 & \text { otherwise }
\end{array}\right. \\
& Q_{a o v}(t)=\left\{\begin{array}{ccc}
\frac{P_{l v}(t)-P_{a o}(t)}{R_{a o v}} & \text { if } & P_{l v}(t)>P_{a o}(t) \\
0 & & \text { otherwise }
\end{array}\right.
\end{aligned}
$$

Finally, the continuity equation gives the rate of volume change inside the compartments as a function of the inflows and outflows:

$$
\begin{aligned}
\frac{d V_{l v}}{d t} & =Q_{m i t}(t)-Q_{a o v}(t) \\
\frac{d V_{S, a o}}{d t} & =Q_{a o v}(t)-Q_{s y s}(t) \\
\frac{d V_{S, v c}}{d t} & =Q_{s y s}(t)-Q_{m i t}(t) .
\end{aligned}
$$

Summing these three equations gives:

$$
\frac{d V_{l v}}{d t}+\frac{d V_{S, a o}}{d t}+\frac{d V_{S, v c}}{d t}=0 .
$$

Equation 13 implies the sum of chamber volumes is a constant for this closedloop system, and is the total amount of blood in the system. The value of this volume is called total stressed blood volume $(S B V)[26]$.

\subsection{Respiratory system model}

The respiratory model must also be minimal to ensure identifiability and computational speed. Many respiratory system models exist [38, 45, 46], including complex, three-dimensional finite element models [39, 47], as well as simpler lumped parameter models [38, 45, 48]. This research considers a clinically validated linear single compartment model [38, 45] (Fig. 1), previously shown to be a globally accurate minimal model of fundamental respiratory mechanics [38] and structurally and practically identifiable [36, 38, 40].

Airway air flow, $Q_{a w}(t)$, is expressed using Poiseuille flow between the ventilator and the lung compartment, yielding [38]:

$$
Q_{a w}(t)=\frac{P_{a w}(t)-P_{l u n g}(t)}{R_{a w}},
$$

where $P_{a w}(t)$ is the ventilator input pressure, $P_{\text {lung }}(t)$ is the pressure inside the lungs, and $R_{a w}$ is the airway resistance. A linear relationship links $P_{\text {lung }}(t)$ and the volume of air inside the lungs, $V_{\text {lung }}(t)$, via the total respiratory system elastance, $E_{r s}$ :

$$
P_{\text {lung }}(t)=E_{\text {rs }} V_{\text {lung }}(t) .
$$


This lung model has been extensively validated against clinical data and captures all fundamental mechanics [37, 38, 41, 48]. An expression of the lung volume can be integrated from the airflow $Q_{a w}(t)$ entering the lungs, as:

$$
V_{\text {lung }}(t)=\int Q_{a w}(t) d t+\frac{P E E P}{E_{r s}},
$$

where the integration constant $\frac{P E E P}{E_{r s}}$ can be found from Equation 15 at endexpiration, when the lung pressure is equal to $P E E P$ and the periodic part of the integral cancels. This constant corresponds to the functional residual capacity of the lung.

By defining a periodic volume $V_{C}(t)=\int Q_{a w}(t) d t$ and by inserting Equations 15 and 16 in Equation 14, yields an expression for $P_{a w}(t)$ :

$$
P_{a w}(t)=R_{a w} Q_{a w}(t)+E_{r s} V_{C}(t)+P E E P .
$$

\subsection{Cardio-pulmonary coupling model}

Cardio-pulmonary coupling is made through intra-thoracic pressure, which is assumed spatially homogeneous in this work. The overall simplified model assumes the ventricular and venous compartments are submitted to intra-thoracic pressure, as reflected in Equations 3 and 4. The arterial compartment is not subjected to $P_{t h}$, as the part of the circulation it represents is not subjected to thoracic pressure in reality. Different versions of these hypotheses have been made for previous cardio-pulmonary models [27, 28]. The hypotheses used in this work are discussed in Appendix A.

The coupling is created using $P_{t h}(t)$, computed from the respiratory model [38], for the pressure over the total thorax volume. The chest wall elastance $E_{\text {wall }}$ links intra-thoracic pressure and lung volume, yielding:

$$
P_{t h}(t)=E_{\text {wall }} V_{\text {lung }}(t) .
$$

The respiratory system elastance is assumed to be mainly composed of the lungs and the chest wall, as two homogeneous compliances in series [49], as represented on the left of Figure 1, yielding:

$$
E_{r s}=E_{\text {lung }}+E_{\text {wall }}
$$

Ultimately, $P_{t h}(t)$ can be derived by substituting Equations 16 and 19 into Equation 18, yielding (cfr. Fig. 8):

$$
P_{t h}(t)=E_{\text {wall }} V_{C}(t)+P E E P \frac{E_{\text {wall }}}{E_{r s}}
$$

In summary, the cardio-pulmonary coupling model has 15 equations: Equations 3 to 12, Equations 14 to 16, and Equation 18; and 16 parameters. The model parameters are summarised in Table 2 . The model has 3 state variables: $V_{l v}(t), V_{a o}(t)$ and $V_{v c}(t)$. The initial condition for each of these variables were $S B V / 3$. 


\subsection{Data}

The experimental data used in this study come from 3 porcine experiments performed in the haemodynamics laboratory of the University of Liège [4]. These experiments were approved by the Ethics Committee of the Medical Faculty of the University of Liège. These experiments analysed the haemodynamic impact of vascular filling by successive fluid administration [4]. Importantly, the experiments were performed with the chest closed to ensure thoracic pressure and cardiopulmonary interactions were not modified.

The pigs weighed $27.3,24.5$ and $20 \mathrm{~kg}$. They were anaesthetised. They were administered a muscle relaxant (Nimbex, GlaxoSmithKline AG, Switzerland) and mechanically ventilated through a tracheostomy while in supine position. The ventilator parameters (GE Engström CareStation, General Electric Healthcare, USA) were:

- Tidal volume of approximately $10 \mathrm{ml} / \mathrm{kg}$,

- Frequency of 20 breaths per minute,

- Initial PEEP $5 \mathrm{cmH}_{2} \mathrm{O}\left(0 \mathrm{cmH}_{2} \mathrm{O}\right.$ for pig 3).

Micromanometer-tipped catheters (Transonic, NY) provided invasive real-time recording of (cfr. Fig. 6):

- Left ventricular pressure, $P_{l v, m}(t)$,

- Left ventricular volume $V_{l v, m}(t)$,

- Aortic pressure, $P_{a o, m}(t)$.

A PiCCO monitor (Pulsion AG, Germany) was also used, its arterial and venous catheters located in the femoral artery and vena cava. After the required calibration step, the PiCCO displayed:

- Maximal and minimal vena cava pressure, $P_{v c, \max }$ and $P_{v c, \min }$

- Cardiac output, $C O$

The mechanical ventilator, in turn, recorded:

- Airway pressure, $P_{a w, m}(t)$,

- Airway flow, $Q_{a w, m}(t)$.

Finally, a Fogarty balloon catheter was inserted in the inferior vena cava.

After all sensors were correctly positioned, PEEP was increased by steps of $5 \mathrm{cmH}_{2} \mathrm{O}$, up to $25 \mathrm{cmH}_{2} \mathrm{O}$. After each change in PEEP, once steady state was reached, the ventilator was turned off and the Fogarty balloon catheter was inflated to reduce ventricular preload - a preload reduction experiment. Two preload reduction experiments were performed at each PEEP level (cfr Fig. 4).

The signals were recorded at $250 \mathrm{~Hz}$ and filtered and split into heartbeats after the experiments. Figure 2 shows the time series of measured airway pressure 
during the whole experiment for pig number 1. The timespans between each PEEP change and the following preload reduction experiment were considered to be physiologically representative of the pigs baseline hemodynamics under mechanical ventilation.

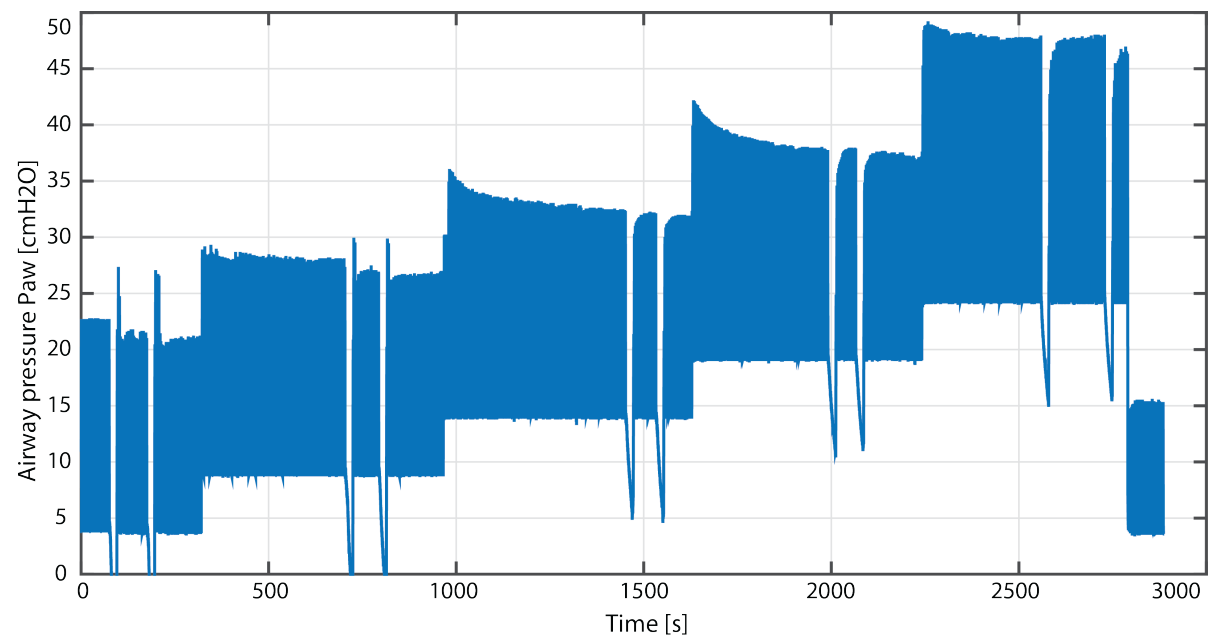

Figure 2: Time series of the airway pressure signal $P_{a w}(t)$ in $\left[\mathrm{cmH}_{2} \mathrm{O}\right]$ for pig 1 . The PEEP changes can be observed by the offset changes in airway pressure. At each each PEEP level, two preload reduction experiments can be observed, when the pressure drops for approximately 20 seconds.

\subsection{Output vector}

Because of the asynchrony and complex interactions between respiratory and CVS signals, the number of heartbeats over one respiratory period is never the same. Therefore, only median values computed over several cardiac and respiratory periods were included in the output vector. This de-coupling of hemodynamics and pulmonary mechanics yields an overall global behavior.

The model presented here is voluntarily oversimplified. Therefore, it was expected the shape of modelled CVS signals would differ from measured signals. Let $X(t)$ and $X_{m}(t)$ be the modelled time series of a signal and its corresponding measured time series, respectively. Since the shape of a given signal directly influences its mean value over a heartbeat, comparing the mean values of $X(t)$ over a heart beat to the mean values of $X_{m}(t)$ over the same heart beat to fit the model to the measurement would result in an inherent error. Median values of signals were thus used instead of means.

Let $X_{\max , i}$ and $X_{\min , i}$ be the maximal and minimal values of the signal $X(t)$ over the heartbeat $i$ spanning the time period $T_{i}$ :

$$
X_{\max , i}=\max _{t \in T_{i}}[X(t)] \quad \text { and } \quad X_{\min , i}=\min _{t \in T_{i}}[X(t)]
$$


The offset, $\bar{X}$, of the signal $X(t)$ over $N=20$ cardiac periods was computed as the average of the medians of $X_{\max , i}$ and $X_{\min , i}$ over $N$ heartbeats:

$$
\bar{X}=\frac{\operatorname{median}_{i=1, \ldots, N}\left(X_{\max , i}\right)+\operatorname{median}_{i=1, \ldots, N}\left(X_{\min , i}\right)}{2}
$$

The 20 cardiac periods were always chosen as the last 20 beats of the baseline dataset, for every PEEP level (cf. Figure 2) both in the modelled and measured signals. The $\operatorname{median}_{i=1, \ldots, N}()$ function was chosen over the mean to minimize the influence of potential outlier values from the sensor measurements.

Similarly, the range, $\Delta X$, of $X(t)$ over $N$ cardiac periods was defined:

$$
\Delta X=\operatorname{median}_{i=1, \ldots, N}\left(X_{\max , i}\right)-\operatorname{median}_{i=1, \ldots, N}\left(X_{\min , i}\right)
$$

Due to the respiratory oscillations in the signal $X(t), X_{\max , i}$ is not constant between heartbeats. Let $X_{\max }^{\max , j}$ and $X_{\max }^{\min , j}$ be the maximal and minimal values of $X_{\max , i}$ during the $j^{\text {th }}$ respiratory period, spanning several cardiac periods. The range of the respiratory oscillations in the signal $X(t)$, written $\Delta X_{\max }$, can thus be calculated:

$$
\Delta X_{\text {max }}=\operatorname{median}_{j}\left(X_{\max }^{\max , j}\right)-\operatorname{median}_{j}\left(X_{\max }^{\min , j}\right)
$$

The calculation of $\Delta X_{\max }$ is exemplified on Figure 3 for $X(t)=P_{a o, m}(t)$.

Let $\mathbf{y}(\mathbf{p})$ be the output vector calculated from the modelled signals resulting from one simulation of the model using the parameter values in $\mathbf{p}$. The components of $\mathbf{y}(\mathbf{p})$, as well as the measurements included in the reference output vector, $\mathbf{y}^{\text {ref }}$ are shown in Table 1 . This table summarizes from which signals the components of these vectors are calculated. Detailed explanations on the choice of the model signals to compute $\mathbf{y}(\mathbf{p})$ are given in Appendix A.

The seventh component of the output vector quantifies the respiratory effects on the aortic pressure waveform. This component is the range of the respiratory oscillations in the aortic pressure signal, written $\Delta P_{a o, m, \max }$, calculated using Equation 24 and exemplified on Figure 3. No information related to left ventricular pressure, $P_{l v}(t)$, was included in the output and reference vectors.

\subsection{Error vector}

A relative error vector, $\mathbf{e}$, between simulated and reference values is defined:

$$
e_{i}=\frac{y_{i}^{r e f}-y_{i}(\mathbf{p})}{y_{i}^{r e f}} \quad \text { for } i=1, \ldots, 7
$$

\subsection{Parameter estimation}

\subsubsection{Introduction}

The model parameters were adjusted to minimise the error between simulated and measured signals. First, nominal values had to be assigned to all model parameters. As a second step, a selected subset of the parameters was iteratively adjusted to further decrease the error. This two-step process was performed for all available datasets, covering all pigs at all PEEP levels. 


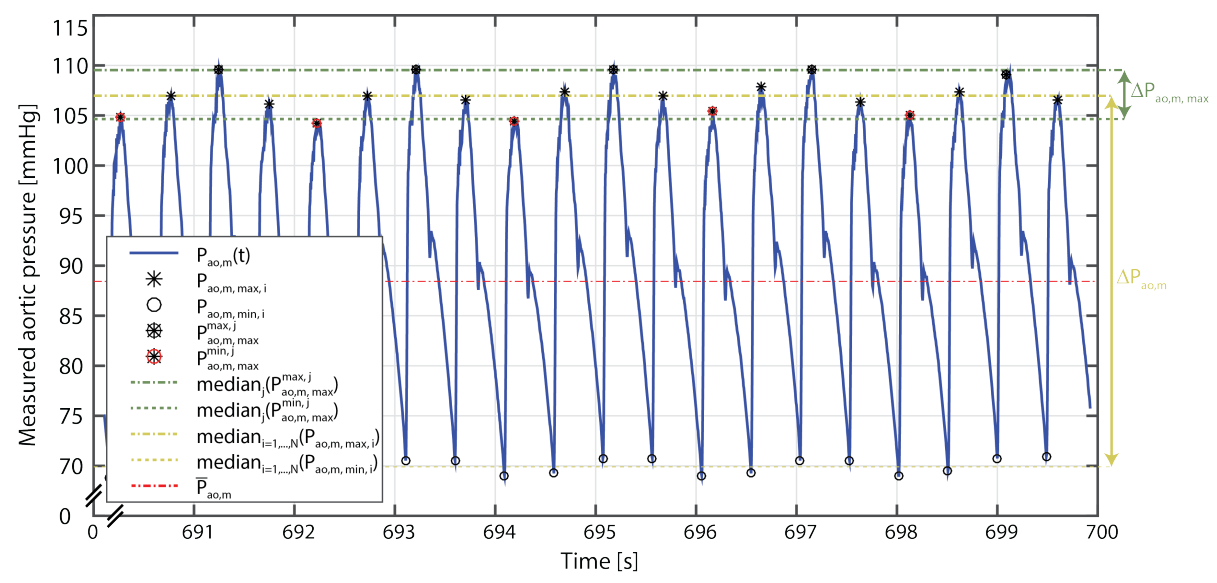

Figure 3: Measured time series of the aortic pressure signal $P_{a o, m}(t)$ (blue line) on pig 1 at PEEP $10 \mathrm{cmH}_{2} \mathrm{O}$. The black asterisk and circle symbols respectively represent the maximal and minimal aortic pressures of each cardiac period $\left(P_{a o, m, \max , i}\right.$ and $\left.P_{a o, m, \min , i}\right)$. The yellow dotted lines show the medians of these values, used to compute $\Delta P_{a o, m}$ (cfr. Eq. 23). The black circled and red circled asterisks are respectively the maximal and minimal peaks in the respiratory oscillations of $P_{a o, m, \max , i}$. The green dotted lines show the medians of these values, used to compute $\Delta P_{a o, m, \max }$ (cfr. Eq. 24). The red dotted line shows the aortic pressure signal offset $\bar{P}_{a o, m}$.

\begin{tabular}{|l|l|l|l|l|}
\hline$i$ & $\begin{array}{l}\text { Model out- } \\
\text { put }\end{array}$ & $y_{i}(\mathbf{p})$ & $y_{i}^{r e f}$ & Calculated from \\
\hline 1 & $P_{a o}(t)+P_{t h}(t)$ & $\bar{P}_{a o}$ & $\bar{P}_{a o, m}$ & $P_{a o, m}(t)$ \\
\hline 2 & $P_{a o}(t)+P_{t h}(t)$ & $\Delta P_{a o}$ & $\Delta P_{a o, m}$ & $P_{a o, m}(t)$ \\
\hline 3 & $P_{v c}(t)-P_{t h}(t)$ & $\bar{P}_{v c}$ & $\bar{P}_{v c, m}$ & $\bar{P}_{v c, m}=\frac{P_{v c, \max }+P_{v c, m i n}}{2}$ \\
\hline 4 & $P_{v c}(t)-P_{t h}(t)$ & $\Delta P_{v c}$ & $\Delta P_{v c, m}$ & $\Delta P_{v c, m}=P_{v c, \max }-P_{v c, \min }$ \\
\hline 5 & $V_{l v}(t)$ & $\bar{V}_{l v}$ & $\bar{V}_{l v, m}$ & $V_{l v, m}(t)$ \\
\hline 6 & $V_{l v}(t)$ & $\Delta V_{l v}$ & $\Delta V_{l v, m}$ & $V_{l v, m}(t)$ \\
\hline 7 & $P_{a o}(t)+P_{t h}(t)$ & $\Delta P_{a o, \max }$ & $\Delta P_{a o, m, \max }$ & $P_{a o, m}(t)$ \\
\hline
\end{tabular}

Table 1: Components of the vectors $\mathbf{y}(\mathbf{p})$ and $\mathbf{y}^{\text {ref }}$. For each simulation of the model for a given set of parameters $\mathbf{p}$, the signals of the second column are used to compute the components of $\mathbf{y}(\mathbf{p})$ (third column) which are compared to $\mathbf{y}^{\text {ref }}$ (fourth column) whose components are calculated from the measured signals of the fifth column.

\subsubsection{Nominal parameter values}

Several methods can be used to compute the nominal values of the parameters, $\mathbf{p}_{0}[4]$. The methods used here are based on models or specific reasoning with respect to the CVS model dynamics. The following eight steps calculate or estimate from data all 16 parameters. 
Step 1 Venous and aortic chamber elastances, $E_{v c}$ and $E_{a o}$ (Parameters \# $1-2)$

The nominal values of the aortic and venous chamber elastances are [4, 26]:

$$
E_{a o, 0}=\frac{\Delta P_{a o, m}}{C O \cdot T} \quad \text { and } \quad E_{v c, 0}=\frac{\Delta P_{v c, m}}{C O \cdot T} .
$$

Where $C O$ is the cardiac output and the product $C O \cdot T$ corresponds to an average stroke volume over the solicitation period. The pressure ranges $\Delta P_{a o, m}$ and $\Delta P_{v c, m}$ are known from the measured signals.

Step 2 Ventricular parameters, $E_{l v, e s}, E_{l v, e d}, V_{l v, d}$ and $V_{l v, u}$ (Parameters \# $3-6)$

The preload reduction experiments performed at each PEEP level allowed estimation of the ventricle-related parameters $E_{l v, e s}, V_{l v, d}, E_{l v, e d}$ and $V_{l v, u}$. To obtain the values of the parameters $E_{l v, e s}$ and $V_{l v, d}$, the iterative method of Kass et al. [50] was implemented. This method performs a linear regression of the points of end-systole, as shown in Figure 4. The method was adapted for the points of end-diastole, thus providing values for $E_{l v, e d}$ and $V_{l v, u}$, as also shown in Figure 4.

Step 3 Driver function parameter $W$ (Parameter \# 7)

During the preload reduction experiments, the ventilator is turned off and the intrathoracic pressure, $P_{t h}$ becomes negligible compared to the cardiac pressures. Therefore, during the preload reduction experiments, the pressure-volume relationship in the left ventricle is approximated:

$$
\begin{aligned}
P_{l v}(t) & \approx P_{l v, f}(t) \\
& =e_{l v}(t) E_{l v, e s}\left(V_{l v}(t)-V_{l v, d}\right)+\left(1-e_{l v}(t)\right) E_{l v, e d}\left(V_{l v}(t)-V_{l v, u}\right)
\end{aligned}
$$

Since $P_{l v, m}(t)$ and $V_{l v, m}(t)$ are measured, and $E_{l v, e s}, V_{l v, d}, E_{l v, e d}$ and $V_{l v, u}$ were computed at Step 2, Equation 27 can be used with the measured signals, to compute the experimental driver function $e_{l v, m}(t)$ :

$$
e_{l v, m}(t)=\frac{P_{l v, m}(t)-E_{l v, e d}\left(V_{l v, m}(t)-V_{l v, u}\right)}{E_{l v, e s}\left(V_{l v, m}(t)-V_{l v, d}\right)-E_{l v, e d}\left(V_{l v, m}(t)-V_{l v, u}\right)}
$$

An example of such an experimental driver function is shown in Figure 5. The parameter $W$ of the driver function could then be computed by fitting Equation 6 on the obtained experimental curve, as exemplified in Figure 5. This fitting step was performed using non-linear least squares.

Step 4 Cardiac period, $T$ (Parameter \# 8)

The cardiac period, $T$, was taken as the average of the cardiac periods of the $N=20$ heartbeats representing the baseline datasets. 
Step 5 Circulatory resistance $R_{\text {sys }}$ (Parameter \# 9)

Let $\langle X\rangle$ be the average value of the signal $X(t)$ over $N=20$ cardiac periods. The nominal value of $R_{s y s}$ is defined [4, 26]:

$$
R_{s y s, 0}=\frac{\left\langle P_{a o, m}\right\rangle-\left\langle P_{v c, m}\right\rangle}{C O} .
$$

Step 6 Valve resistances $R_{m i t}$ and $R_{a o v}$ (Parameters \# 10-11)

The values of the valve resistances were set as follows:

$$
R_{m i t}=0.001 \mathrm{mmHg} \cdot \mathrm{s} / \mathrm{ml} \text { and } \quad R_{\text {aov }}=0.04 \mathrm{mmHg} \cdot \mathrm{s} / \mathrm{ml}[29]
$$

The mitral valve resistance was chosen to be low as the measured venous pressures were quite low, which could hamper the opening of the mitral valve in the model equations ( $c f$. Equation 8).

Step 7 Total stressed blood volume, SBV (Parameter \# 12)

The value of total stressed blood volume, $S B V$, was calculated as the sum of average stressed blood volumes inside the chambers (cfr Equation 13) over $N=20$ heartbeats. By writing $\langle X(t)\rangle$ the average over $N=20$ heartbeats of a signal $X(t), S B V$ can be estimated as follows:

$$
S B V=\left\langle V_{S, l v}\right\rangle+\left\langle V_{S, a o}\right\rangle+\left\langle V_{S, v c}\right\rangle
$$

For the venous and arterial chambers, average volumes were estimated from the offset pressures over $N=20$ heartbeats (cfr Equation 22), accounting for the elastances. Putting Equation 2 into 1 and solving for stressed blood volumes and neglecting intrathoracic pressure, estimates of $\left\langle V_{S, a o}\right\rangle$ and $\left\langle V_{S, v c}\right\rangle$ are found:

$$
\left\langle V_{S, a o}\right\rangle=\frac{\bar{P}_{a o, m}}{E_{a o, 0}} \quad \text { and } \quad\left\langle V_{S, v c}\right\rangle=\frac{\bar{P}_{v c, m}}{E_{v c, 0}}
$$

For the ventricle chamber, the average volume over $N=20$ heartbeats was estimated as follows (neglecting intrathoracic pressure):

$$
\left\langle V_{S, l v}\right\rangle \approx\left\langle e_{l v, m}\right\rangle\left(\bar{V}_{l v, m}-V_{l v, d}\right)+\left(1-\left\langle e_{l v, m}\right\rangle\right)\left(\bar{V}_{l v, m}-V_{l v, u}\right)
$$

Equation 32 can be written:

$S B V \approx\left\langle e_{l v, m}\right\rangle\left(\bar{V}_{l v, m}-V_{l v, d}\right)+\left(1-\left\langle e_{l v, m}\right\rangle\right)\left(\bar{V}_{l v, m}-V_{l v, u}\right)+\frac{\bar{P}_{a o, m}}{E_{a o, 0}}+\frac{\bar{P}_{v c, m}}{E_{v c, 0}}$

The value of $S B V$ can thus be estimated from the available measurements and previously computed parameters: $E_{a o, 0}$ and $E_{v c, 0}$ were computed at Step 1, and $V_{l v, d}$ and $V_{l v, u}$ were computed at Step 2. 
Step 8 Ventilation parameters $R_{a w}, E_{r s}, P E E P$, and $E_{\text {wall }}$ (Parameters \# 13-16)

From the ventilator signals, $Q_{a w, m}(t)$ and $P_{a w, m}(t)$, one can use a linear regression of the respiratory system model (Equation 17) to compute the values of the airway flow resistance, $R_{a w}$, and the respiratory system elastance, $E_{r s}$, as previously described $[37,38,41]$. The nominal value of $E_{\text {wall }}$ was taken as $E_{r s}$ and the PEEP was read from the ventilator.

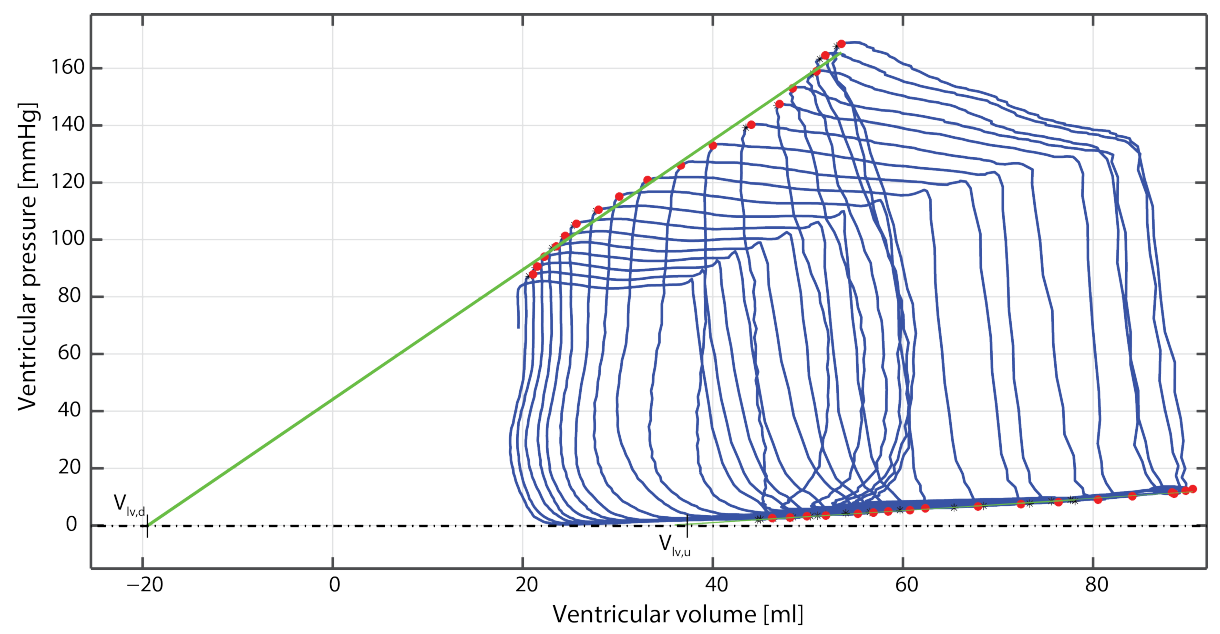

Figure 4: Typical pressure-volume loops during a preload reduction experiment for pig 2 at PEEP $10 \mathrm{~cm} \mathrm{H}_{2} \mathrm{O}$. All collected left ventricular pressure-volume loops had a similar shape to the one presented here, and are shown in Appendix B. The markers show the end-systolic (top left of the loops) and end-diastolic points (bottom-right) and their linear regressions.

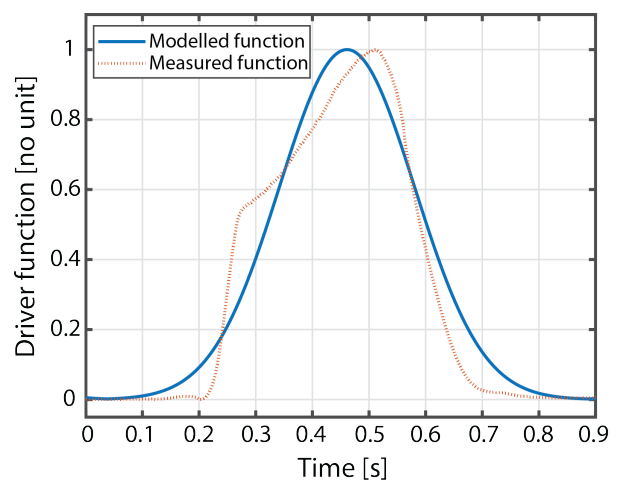

Figure 5: Measured (dotted line) and modelled (plain line) driver functions, using a Gaussian curve. The experimental signal comes from pig 2 data at PEEP $10 \mathrm{cmH}_{2} \mathrm{O}$. 


\subsubsection{Iterative estimation of a parameter subset}

After nominal parameter estimations (Steps 1-8), a subset, $\mathbf{p}^{\prime}$, of $\mathbf{p}$ was further optimised:

$$
\mathbf{p}^{\prime}=\left\{E_{a o}, E_{v c}, R_{s y s}, E_{\text {wall }}, E_{l v, e d}\right\} .
$$

The criteria for including the parameters in $\mathbf{p}^{\prime}$ were based on previous sensitivity analyses [13] and observations from model simulations. In particular, the three-chamber model is not very sensitive to both valve resistances [13], as large changes in value do not imply large changes in the outputs. Therefore, the values of these resistances were kept fixed. In addition, it was often observed that measured vena cava pressure was lower than measured minimum left ventricular pressure. While this situation is physiologically possible, in the model, it blocks ventricular filling and causes difficulty in parameter estimation. The end-diastolic elastance, $E_{l v, e d}$, directly influences minimum ventricular pressure: if it decreases, so does the minimum pressure, for a given volume. Therefore, including $E_{l v, e d}$ in $\mathbf{p}$ gives the iterative process a means to directly control the minimum ventricular pressure, and can thus compensate for impaired ventricular filling in the model.

The parameters in $\mathbf{p}^{\prime}$ were iteratively adjusted to match model outputs to measured data. The parameter estimation routine was started using a rapid, proportional-gain algorithm described in [15, 17]. The resulting parameters were then finely tuned using the non-linear simplex algorithm [51]. The cost function to be minimised was the 1 -norm of the error vector, $\|\mathbf{e}\|_{1}$.

\subsubsection{Summary}

Table 2 summarizes the model parameters and the methods used to estimate their values. The overall iterative parameter estimation procedure can be summarised in the following steps:

A. Computation of nominal parameter values from the available measurements (Steps 1-8).

B. Model simulation using the current parameter values and computation of the output vector $\mathbf{y}(\mathbf{p})$.

C. Computation of the error vector, e, as the relative difference between $\mathbf{y}(\mathbf{p})$ and the reference values, $\mathbf{y}^{\text {ref }}$.

D. Adjust the parameters in $\mathbf{p}^{\prime}$ using the proportional and simplex methods and repeat steps $\mathrm{B}$ to $\mathrm{D}$.

E. Output the optimal, pig-specific parameter values, $\mathbf{p}_{\text {opt }}$.

\section{Results}

\subsection{Quality of the parameter fitting}

Table 3 shows the minimum average absolute error, $\|\mathbf{e}\|_{1} / 7$, for each PEEP level and each pig. Appendix $\mathrm{C}$ presents the corresponding values of all the components of e. Appendix D and Appendix E respectively contain the reference values of all the datasets considered in this study and the model parameter estimations on those datasets. 


\begin{tabular}{|c|c|c|c|c|}
\hline$\#$ & Parameter & $\begin{array}{l}\text { Method } \\
\text { to obtain } \\
\text { nominal } \\
\text { value }\end{array}$ & $\begin{array}{l}\text { Measurements } \\
\text { / parameters } \\
\text { used to obtain } \\
\text { nominal value }\end{array}$ & $\begin{array}{l}\text { Iteratively } \\
\text { adjusted }\end{array}$ \\
\hline 1 & $E_{v c}(\mathrm{mmHg} / \mathrm{ml})$ & Equation 26 & $\Delta P_{v c, m}, C O$ & Yes \\
\hline 2 & $E_{a o}(\mathrm{mmHg} / \mathrm{ml})$ & Equation 26 & $\Delta P_{a o, m}, C O$ & Yes \\
\hline 3 & $E_{l v, e s}(\mathrm{mmHg} / \mathrm{ml})$ & Kass et al. [52] & $P_{l v, m}, V_{l v, m}$ & No \\
\hline 4 & $E_{l v, e d}(\mathrm{mmHg} / \mathrm{ml})$ & Kass et al. [52] & $P_{l v, m}, V_{l v, m}$ & Yes \\
\hline 5 & $V_{l v, d}(\mathrm{ml})$ & Kass et al. [52] & $P_{l v, m}, V_{l v, m}$ & No \\
\hline 6 & $V_{l v, u}(\mathrm{ml})$ & Kass et al. [52] & $P_{l v, m}, V_{l v, m}$ & No \\
\hline 7 & $W\left(\mathrm{~s}^{-2}\right)$ & $\begin{array}{l}\text { Linear } \\
\text { regression of } \\
\text { Equation } 6, \\
\text { with } \\
\text { Equation } 29\end{array}$ & $\begin{array}{l}P_{l v, m}, V_{l v, m}, \\
E_{l v, e d}, V_{l v, u}, \\
E_{l v, e s}, V_{l v, d}\end{array}$ & No \\
\hline 8 & $T(\mathrm{~s})$ & Average & $P_{l v, m}, V_{l v, m}$ & No \\
\hline 9 & $R_{\text {sys }}(\mathrm{mmHg} \mathrm{s} / \mathrm{ml})$ & Equation 30 & $\begin{array}{l}\bar{P}_{a o, m}, \bar{P}_{v c, m} \\
C O\end{array}$ & Yes \\
\hline 10 & $R_{\text {mit }}(\mathrm{mmHg} \mathrm{s} / \mathrm{ml})$ & 0.001 & - & No \\
\hline 11 & $R_{\text {aov }}(\mathrm{mmHg} \mathrm{s} / \mathrm{ml})$ & 0.04 & - & No \\
\hline 12 & $S B V(\mathrm{ml})$ & Equation 35 & $\begin{array}{l}e_{l v, m}, V_{l v, m}, \\
V_{l v, d}, V_{l v, u}, \\
P_{a o, m}, E_{a o}, \\
P_{v c, m}, E_{v c}\end{array}$ & No \\
\hline 13 & $R_{a w}(\mathrm{mmHg} \mathrm{s} / \mathrm{ml})$ & $\begin{array}{l}\text { Linear } \\
\text { regression of } \\
\text { Equation } 17\end{array}$ & $\begin{array}{l}P_{a w, m}, Q_{a w, m}, \\
P E E P\end{array}$ & No \\
\hline 14 & $E_{r s}(\mathrm{mmHg} / \mathrm{ml})$ & $\begin{array}{l}\text { Linear } \\
\text { regression of } \\
\text { Equation } 17\end{array}$ & $\begin{array}{l}P_{a w, m}, Q_{a w, m}, \\
P E E P\end{array}$ & No \\
\hline 15 & $P E E P\left(\mathrm{cmH}_{2} \mathrm{O}\right)$ & $\begin{array}{l}\text { From the } \\
\text { ventilators }\end{array}$ & - & No \\
\hline 16 & $E_{\text {wall }}(\mathrm{mmHg} / \mathrm{ml})$ & Equal to $E_{r s}$ & $E_{r s}$ & Yes \\
\hline
\end{tabular}

Table 2: List of model parameters and methods used to determine their values.

\subsection{Model dynamics}

Figure 6 shows simulated pressures and volumes using the estimated parameter values listed in Table 4. In particular, the bottom right panel of Figure 6 shows the corresponding left ventricular pressure-volume loop.

\subsection{Reaction to changes in parameters}

The model reaction to specific changes in parameters was also analysed. More specifically, the following parameter changes were implemented: 


\begin{tabular}{l|rrrrrr} 
Pigs & PEEP 0 & PEEP 5 & PEEP 10 & PEEP 15 & PEEP 20 & PEEP 25 \\
\hline Pig 1 & $/$ & $5.4 \%$ & $1.21 \%$ & $2.28 \%$ & $8.88 \%$ & $13.98 \%$ \\
Pig 2 & $/$ & $0.66 \%$ & $2.3 \%$ & $9.76 \%$ & $19.07 \%$ & $15.76 \%$ \\
Pig 3 & $5.3 \%$ & $13.92 \%$ & $17.16 \%$ & $13.54 \%$ & $25.75 \%$ & $18.23 \%$
\end{tabular}

Table 3: Average absolute value error $\|\mathbf{e}\|_{1} / 7$ after iterative parameter estimation on the different datasets. No data was recorded on pigs 1 and 2 at PEEP $0 \mathrm{cmH}_{2} \mathrm{O}$
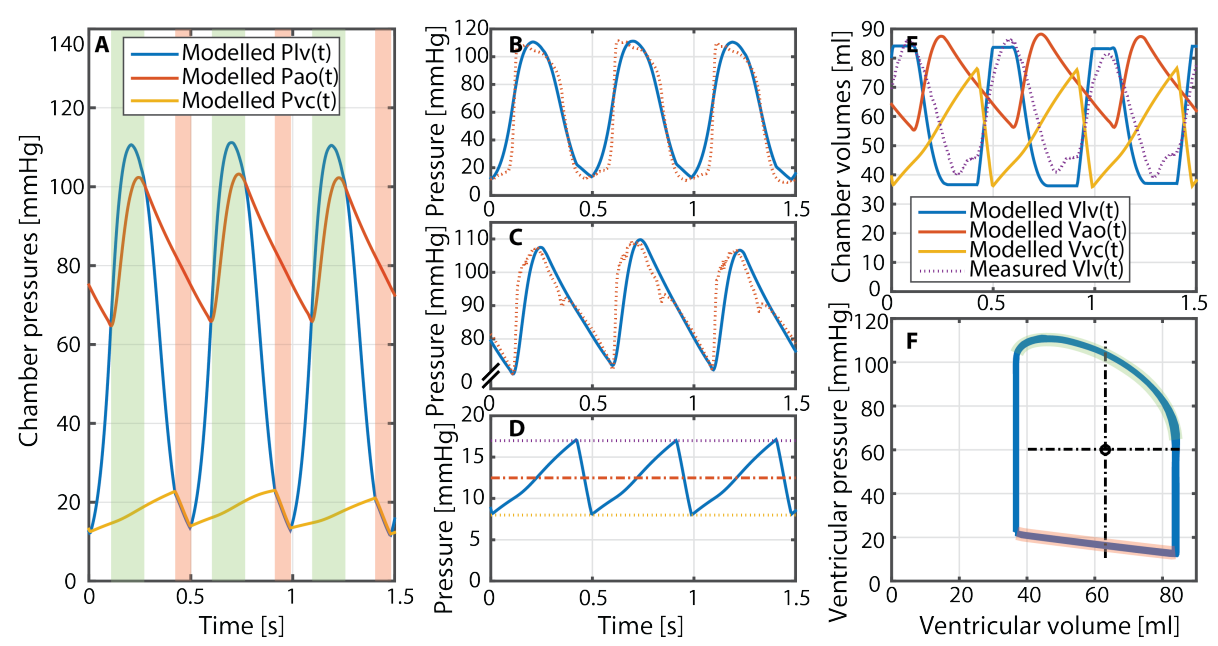

Figure 6: Model output, simulated with the values listed in Table 4. The green and red areas highlight the aortic and mitral valve openings (respectively). A) Modelled chamber pressures driving the opening and closure of the valves. B) Modelled ventricular pressure $P_{l v}(t)$ (blue line) and measured ventricular pressure (dotted line). C) Modelled signal $P_{a o}(t)+P_{t h}(t)$ (blue line) used for parameter estimation, compared to the measured aortic pressure (dotted line). D) Modelled signal $P_{v c}(t)-P_{t h}(t)$ (blue line) used for parameter estimation, compared to the PiCCO reference value for $P_{v c, \max }$ and $P_{v c, \text { min }}$ (dotted lines) and $\bar{P}_{v c}$ (dash-dotted line). E) Modelled volumes (plain lines) and measured ventricular volume (dotted line). F) Ventricular PV loops (blue line). The circle represents the $\left(\bar{V}_{l v}, \bar{P}_{l v}\right)$ reference point computed from the measured ventricular signals as explained in Section 2.5. The dash-dotted lines represent the measured pressure and volume ranges, computed as explained in Section 2.5.

- An increase of systemic vascular resistance from $0.7 \mathrm{mmHg} . \mathrm{s} / \mathrm{ml}$ to $1 \mathrm{mmHg} . \mathrm{s} / \mathrm{ml}$.

- An increase of aortic elastance from 1.17 to $1.3 \mathrm{mmHg} / \mathrm{ml}$.

The effect of these two changes on simulated aortic pressure is shown in Figure 7.

\subsection{Influence of the respiration}

Figure 8 shows measured airway pressure, $P_{a w, m}(t)$, and simulated thoracic pressure, $P_{t h}(t)$. It also emphasises the variations of ventricular pressure caused by mechanical ventilation, both in the model and in the data. 


\begin{tabular}{ll|r|r}
\multicolumn{2}{l|}{ Haemodynamic and respiratory parameters } & Value & Units \\
\hline Elastances & $E_{l v, e s}$ & 2.147 & $\mathrm{mmHg} / \mathrm{ml}$ \\
& $E_{l v, e d}$ & 0.053 & $\mathrm{mmHg} / \mathrm{ml}$ \\
& $E_{a o}$ & 1.170 & $\mathrm{mmHg} / \mathrm{ml}$ \\
Respiratory system & $E_{v c}$ & 0.224 & $\mathrm{mmHg} / \mathrm{ml}$ \\
& $E_{\text {wall }}$ & 0.011 & $\mathrm{mmHg} / \mathrm{ml}$ \\
Resistances & $E_{r s}$ & 0.021 & $\mathrm{mmHg} / \mathrm{ml}$ \\
& $P E E P$ & 7.356 & $\mathrm{mmHg}$ \\
Driver function & $R_{\text {sys }}$ & 0.699 & $\mathrm{mmHg} \cdot \mathrm{s} / \mathrm{ml}$ \\
& $R_{\text {aov }}$ & 0.04 & $\mathrm{mmHg} \cdot \mathrm{s} / \mathrm{ml}$ \\
& $R_{\text {mit }}$ & 0.001 & $\mathrm{mmHg} \cdot \mathrm{s} / \mathrm{ml}$ \\
ESPVR \& EDPVR & $V_{l v, d}$ & 59.970 & $\mathrm{~s}^{-2}$ \\
& $S$ & 0.442 & $\mathrm{~s}$ \\
& $V_{l v, u}$ & 0.491 & $\mathrm{~s}$ \\
& & -9.244 & $\mathrm{ml}$ \\
& & 41.532 & $\mathrm{ml}$
\end{tabular}

Table 4: Example of estimated parameter values for pig 1 at PEEP $10 \mathrm{cmH}_{2} \mathrm{O}$.
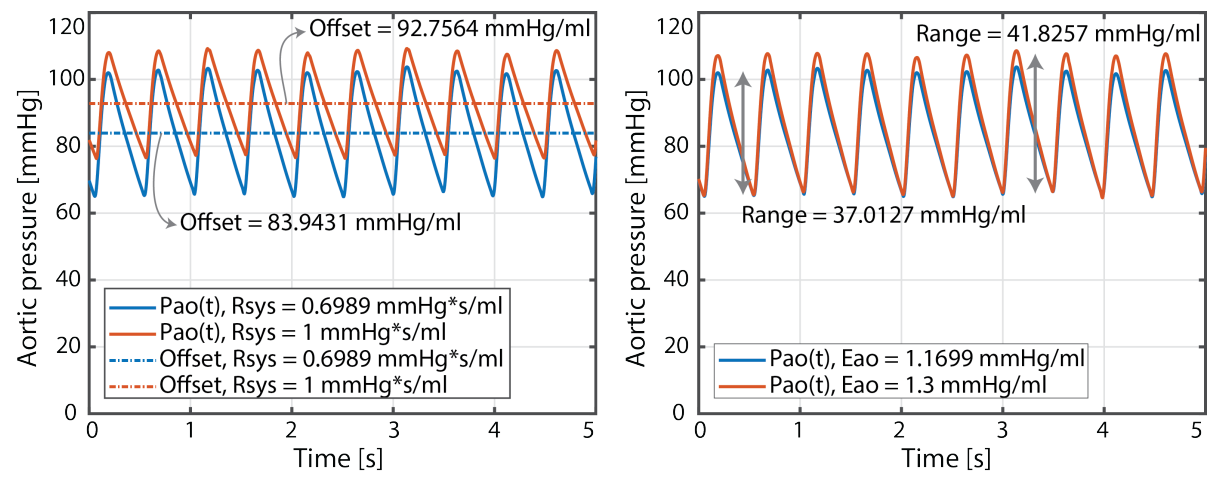

Figure 7: Effect of the variation of $R_{s y s}$ (left) and $E_{a o}$ (right) on the simulated aortic pressure.

Modelled intrathoracic pressure $P_{t h}(t)$, is computed from the measured airway pressure $P_{a w, m}(t)$ using Equation 20. The horizontal dash-dotted lines in Figure 8 A respectively show the values of $P_{t h}(t)$ (blue line) and $P_{a w, m}(t)$ (orange line) at end-expiration, being equal to $P E E P * E_{r s} / E_{\text {wall }}$ and $P E E P$, respectively, as dictated by Equations 16 and 17 .

\section{Discussion}

\subsection{Model dynamics}

The four phases of the cardiac cycle can be distinguished on the fitted model pressure-volume loop of Figure 6 (bottom right panel). This loop can be under- 

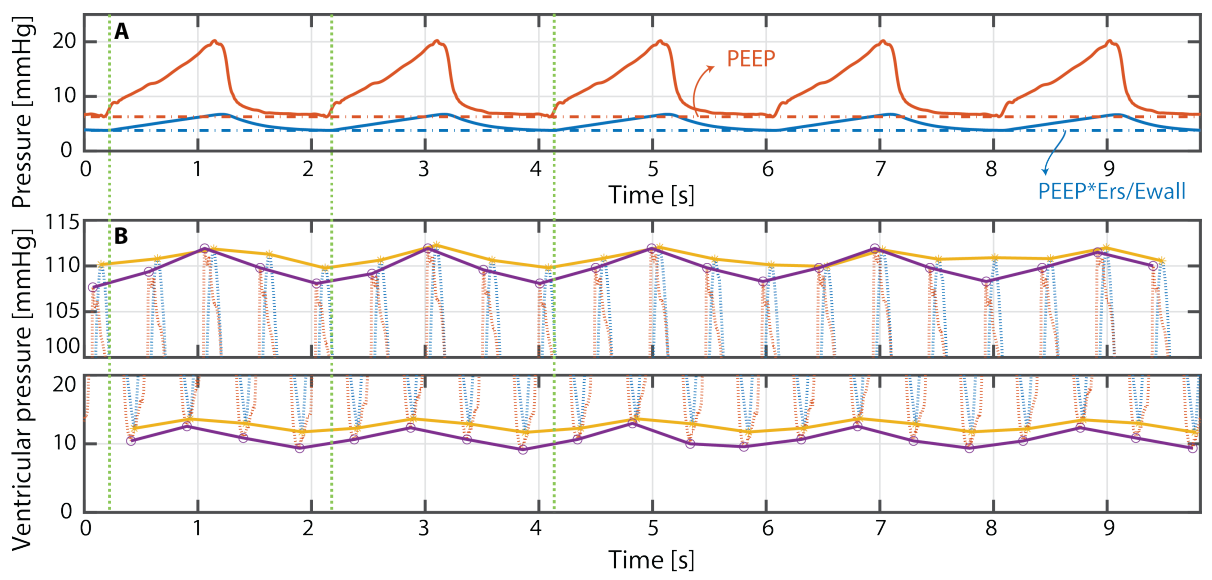

Figure 8: Influence of mechanical ventilation on the cardiovascular signals, both in the model and in the data for pig 1 at PEEP $10 \mathrm{cmH}_{2} \mathrm{O}$. A Simulated intrathoracic pressure, $P_{t h}(t)$ (blue line) and measured airway pressure, $P_{a w, m}(t)$ (orange line). The dash-dotted lines show the values of these two signals at end-expiration. B Simulated (blue dotted line) and measured (orange dotted line) ventricular pressures, $P_{l v}(t)$ and $P_{l v, m}(t)$. B-Top: The yellow linked asterisk and purple linked circle markers show the end-systole points of $P_{l v}(t)$ and $P_{l v, m}(t)$, respectively. B-Bottom: The yellow linked asterisk and purple linked circle markers show the end-diastole points of $P_{l v}(t)$ and $P_{l v, m}(t)$, respectively. The vertical dotted green lines highlight two breathing periods.

stood by comparing the left and top right panels of Figure 6 .

This description of the cardiac cycles generated by the model matches all expectations and shows that the model, despite its simplicity, captures the fundamental CVS dynamics [53].

\subsection{Influence of respiration}

A full and consistent validation of the model requires the model behaves physiologically over several heartbeats and breathing cycles. Figure 8B clearly shows the influence of the respiratory wave (intrathoracic pressure) on the simulated ventricular pressure, in a similar pattern as observed on the data. Indeed, ventricular pressure is clearly modulated by the respiratory wave. The heartbeats at the end of expiration (respectively inspiration) involve lower (respectively higher) ventricular pressures. This phenomenon is highlighted in Figure $8 \mathrm{~B}$ on the ventricular pressure maxima and minima mainly because the magnitude of the respiration-induced changes in ventricular pressure is relatively small compared to ventricular pressure itself.

Both in the data and the model, the expected mechanical influence of intrathoracic pressure on ventricular volume was observed. Volumes at end-filling are lower at the end of inspiration because intra-thoracic pressure is higher, which decreases ventricular filling. This behaviour was observed in the data and reflected by the model. However, other external complex factors can influence 
volumetric changes in the ventricle, which are not captured by the simplified dynamics of this model. Therefore, the influence of the intra-thoracic pressure on the ventricular volume in the model was expected not to be as exact to physiological reality as the respiratory influence on the ventricular pressure.

\subsection{Parameter estimation process}

As shown in Table 3, the model outputs were fitted on reference data with relatively small fitting errors. The mean fitting error roughly increases with PEEP, for each pig. Consequently, at low PEEP, the model can represent the complexity of the measured haemodynamic signals, even if it involves very strong assumptions. In contrast, the model is reaching its limits at higher PEEP values, which might induce other strong biophysical events [54] altering the cardiopulmonary interactions in such a way the model defined is no longer relevant. Such high PEEP levels $\left(25 \mathrm{cmH}_{2} \mathrm{O}\right)$ are typically not used in critically ill patients [55].

Finally, the ranges of the average absolute error values (cf. Table 3 ) are still relatively low, considering the strong assumptions. These errors are comparable to the fitting errors obtained during the parameter estimation of much more complex CVS models using a partly common output vector [3, 29]. This results clearly shows there is no loss of fitting quality for these signals using simpler models.

As shown in Table 4, Figure 4 and Table E.7, negative values were obtained for the parameter $V_{l v, d}$ on several PEEP levels for the three pigs. These results show the linear ESPVR model commonly adopted in the literature may not be exact or most relevant. Therefore, this parameter cannot be interpreted as a physical volume. Negative values compensate inaccuracy of the commonly used linear ESPVR model and should not be given a physical interpretation. This observation has been made by several other researchers $[4,52,56]$.

\subsection{Effect of PEEP on the haemodynamic parameters}

The estimation of pig-specific parameter values for the model enables relating PEEP levels to these parameters. Thus, observation of haemodynamic effects of PEEP changes becomes possible. Figure 9 shows the estimated values of $R_{s y s}$ and $E_{v c}$ as a function of the PEEP level. The systemic resistance seems to decrease with the PEEP level. However, the very low values of $R_{s y s}$ at high PEEP levels may also reflect the difficulties of the parameter estimation process at high PEEP, as shown in Table 3. The decrease of $R_{\text {sys }}$ for increasing PEEP also shows that too high PEEP levels may block circulation through the systemic capillaries and confirms previous model-based results [30].

The right panel of Figure 9 shows the estimated value of vena cava elastance, $E_{v c}$, as approximately constant over PEEP, which was also observed for aortic elastance, $E_{a o}$, as shown in Appendix E. Such behaviours can be expected, since elastances indicate the deformability of a vessel, and are thus mechanical properties. The linear model used for the aortic and venous chambers was thus appropriate. 

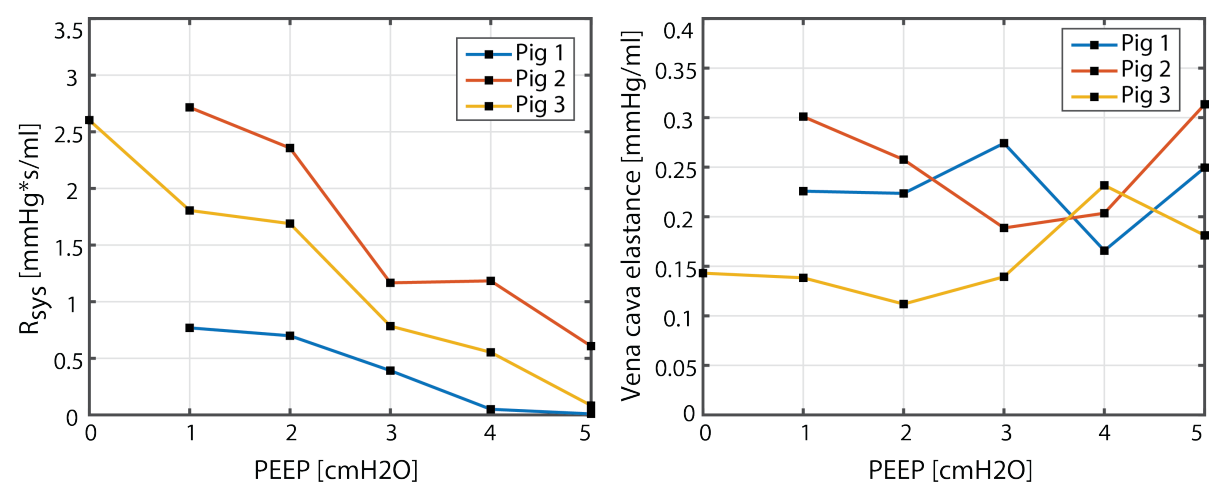

Figure 9: Estimated values of $R_{s y s}$ (left) and $E_{v c}$ (right) on every PEEP level of the three pigs.

\subsection{Reaction to changes in parameters}

Physiologically, an increase in systemic vascular resistance means blood circulates less easily from the aorta to systemic capillaries, increasing aortic pressure [16]. As shown in Figure 7 (left), the model reproduces this behaviour. An increase in aortic elastance makes the aorta more rigid, so, for a given aortic blood volume, the aorta will generate larger pressures. Figure 7 (right) confirms the model also reproduces this behaviour.

\subsection{Limitations}

\subsubsection{Differences between porcine and human physiology}

In this work, parameter estimation was performed using porcine data. There are differences between porcine and human physiology. However, the features used in this work to model the cardiovascular and respiratory systems are common to both species. Indeed, both the human [6] and porcine [3] hearts can be modelled as a single elastic chamber. The same is true for the aorta and the vena cava. Similarly, the respiratory systems of both species have often been modelled using a single linear elastic compartment [6].

A related limitation of this work is the animals were not critically ill. Even if not critically ill, the three pigs exhibited large variability and the model was successfully fit. Further, the three-chamber CVS model used in this work has also successfully been applied to data of pigs in septic shock [14]. These observations indicate the cardio-pulmonary model presented will also fit various situations of pathological human physiology.

\subsubsection{Simple model}

The biggest limitation of the three-chamber CVS model presented in this work is the difficulty to interpret it in terms of cardio-vascular physiology due to its significant abstraction. The CVS in reality consists of two parallel circuits, the systemic and pulmonary circulations, which are traditionally accounted for 
in CVS models [3, 9-12]. In this work, the pulmonary circulation is not represented in the model. This approach assumes the pulmonary circulation behaves as a simple flow resistor, as in other works [14,31-33]. The three-chamber model is thus not suited for studies investigating the pulmonary circulation. However, it is well suited for this type of study of global haemodynamics.

Equally, this three-chamber CVS model is the simplest possible. It thus has the lowest possible number of parameters enhancing identifiability with typical ICU data. Hence, this smaller model maximizes identifiability of global haemodynamics, necessitating increased simplicity and abstraction.

\subsection{Availability of the reference measurements from ICU data}

The output vector used in this study contains seven indices, which can be readily derived in a standard ICU environment:

- Mean left ventricular volume, $\left\langle V_{l v, m}\right\rangle$, is not directly available in an ICU setting. However, it can be approximated from available ICU data, such as global end-diastolic volume and $S V$ [13].

- $S V$, in turn, can clinically be obtained using thermodiluton or echocardiography [34].

- Systemic arterial pressure, $P_{a o, m}(t)$, can be obtained in the ICU using an arterial line. This continuous measurements allows the computation of $\bar{P}_{a o, m}, \Delta P_{a o, m}$, and $\Delta P_{a o, m a x, m}$, as described in Section 2.5.

- Similarly, central venous pressure, $P_{v c, m}(t)$, is usually provided by a central venous line. Its offset, $\bar{P}_{v c, m}$, and range, $\Delta P_{v c, m}$, can then be derived exactly as for $\bar{P}_{a o, m}$ and $\Delta P_{a o, m}$.

The parameter estimation procedure presented in this work can thus be applied using data available in the ICU.

In this work, additional data were used, such as ventricular pressures and volumes during a preload reduction manoeuvre, to get as precise nominal parameter values as possible. Such data is usually not available in an ICU. Consequently, for a clinical application, other methods must be used for estimating initial parameter values. For instance, one may use population-based values, or the values presented in this work. Other methods for obtaining initial parameter values for the CVS model have also been presented [13].

\section{Conclusions}

A new minimal model of the CVS was coupled to a simple model of the respiratory system, through the intrathoracic pressure. The full model was able to capture the combined dynamics of these two physiological systems. Additionally, the model was validated against experimental data. By fitting the model outputs on physiological signals, subject-specific parameter values could 
be estimated. The influence of PEEP on hemodynamic parameters could be established. For instance, this study demonstrated that the systemic resistance of the CVS decreases for increasing PEEP, while the vena cava elastance remains constant.

Due to its simple nature and mathematical expression, the model designed in this study allows observing the effect of ventilatory settings on hemodynamic parameters. This work allowed better quantification of the interactions between the respiratory and the cardiovascular systems. Therefore, it opens many research opportunities in its implementation at the patients bedside and in the optimisation of ventilation parameters by taking into account and predicting ventilation impacts on the CVS.

\section{Acknowledgements}

Sebastien de Bournonville was supported by a PhD grant of the Research

Foundation Flanders (FWO, Grant No. 1S67217N, www.fwo.be). Antoine Pironet was funded by a doctoral research fellowship from the Belgian Funds for Scientific Research (F.R.S.-FNRS) with reference number FC 92044.

\section{References}

[1] A. Esteban, A. Anzueto, I. Alia, F. Gordo, C. Apezteguia, F. Palizas, D. Cide, R. Goldwaser, L. Soto, G. Bugedo, C. Rodrigo, J. Pimentel, G. Raimondi, and M. J. Tobin, "How is mechanical ventilation employed in the intensive care unit? An international utilization review," Am. J. Respir. Crit. Care Med., vol. 161, pp. 1450-1458, May 2000.

[2] N. Soni and P. Williams, "Positive pressure ventilation: what is the real cost?," Br J Anaesth, vol. 101, pp. 446-457, Oct 2008.

[3] C. Starfinger, J. G. Chase, C. E. Hann, G. M. Shaw, P. Lambert, B. W. Smith, E. Sloth, A. Larsson, S. Andreassen, and S. Rees, "Model-based identification of PEEP titrations during different volemic levels," Comput Methods Programs Biomed, vol. 91, pp. 135-144, Aug 2008.

[4] A. Pironet, D. T., J. Chase, M. P., and P. Dauby, "Model-based computation of total stressed blood volume from a preload reduction manoeuvre," Mathematical Biosciences, vol. 265, pp. p. 28-39, 2015.

[5] J. A. Revie, D. Stevenson, J. G. Chase, C. J. Pretty, B. C. Lambermont, A. Ghuysen, P. Kolh, G. M. Shaw, and T. Desaive, "Evaluation of a modelbased hemodynamic monitoring method in a porcine study of septic shock," Comput Math Methods Med, vol. 2013, p. 505417, 2013.

[6] L. B., van Putten M., de Keijzer A., P. P., and van Oostrom J., "A mathematical model for the prediction of fluid responsiveness," Cardiovascular engineering and technology, vol. 4, no. 1, pp. 53-62, 2013. 
[7] H.-H. Fan and M. Khoo, "Pneuma - a comprehensive cardiorespiratory model," in Engineering in Medicine and Biology, 2002. 24th Annual Conference and the Annual Fall Meeting of the Biomedical Engineering Society EMBS/BMES Conference, 2002. Proceedings of the Second Joint.

[8] J. G. Chase, J. C. Preiser, J. L. Dickson, A. Pironet, Y. S. Chiew, C. G. Pretty, G. M. Shaw, B. Benyo, K. Moeller, S. Safaei, M. Tawhai, P. Hunter, and T. Desaive, "Next-generation, personalised, model-based critical care medicine: a state-of-the art review of in silico virtual patient models, methods, and cohorts, and how to validation them," Biomed Eng Online, vol. 17, p. 24, Feb 2018.

[9] Z. Samar, T. Heldt, G. Verghese, and R. Mark, "Model-based cardiovascular parameter estimation in the intensive care unit," pp. $635-638,10$ 2005.

[10] T. Heldt, E. B. Shim, R. D. Kamm, R. G. Mark, and R. D. Kamm, "Computational modeling of cardiovascular response to orthostatic stress," $J$. Appl. Physiol., vol. 92, pp. 1239-1254, Mar 2002.

[11] M. Ursino, "A mathematical model of the carotid baroregulation in pulsating conditions," IEEE Trans Biomed Eng, vol. 46, pp. 382-392, Apr 1999.

[12] J. Messerges, "Modeling systolic pressure variation due to positive pressure ventilation," Conf Proc IEEE Eng Med Biol Soc, vol. 1, pp. 1806-1809, 2006.

[13] A. Pironet, P. Docherty, P. Dauby, J. Chase, and T. Desaive, "Practical identifiability analysis of a minimal cardiovascular system model.," Comput Methods Programs Biomed, January 2017.

[14] A. Pironet, P. Dauby, P. Morimont, N. Janssen, J. Chase, S. Davidson, and T. Desaive, "Model-based decision support algorithm to guide fluid resuscitation," IFAC-PapersOnLine, vol. 49, no. 5, pp. 224-229, 2016.

[15] A. Pironet, Model-Based Prediction of the Response to Vascular Filling Therapy. PhD thesis, Universit de Lige, 2016.

[16] B. W. Smith, J. G. Chase, R. I. Nokes, G. M. Shaw, and G. Wake, "Minimal haemodynamic system model including ventricular interaction and valve dynamics," Medical engineering $\& 3$ physics, vol. 26, no. 2, pp. 131-139, 2004.

[17] J. A. M. Revie, Model-based cardiovascular monitoring in critical care for improved diagnosis of cardiac dysfunction. PhD thesis, University of Canterburry, Christchurch, New Zealand, October 2012. 
[18] C. Starfinger, Patient-Specific Modelling of the Cardiovascular System for Diagnosis and Therapy Assistance in Critical Care. $\mathrm{PhD}$ thesis, University of Canterburry, Christchurch, New Zealand, April 2008.

[19] L. Fresiello, G. Ferrari, A. Di Molfetta, K. Zieli?ski, A. Tzallas, S. Jacobs, M. Darowski, M. Kozarski, B. Meyns, N. S. Katertsidis, E. C. Karvounis, M. G. Tsipouras, and M. G. Trivella, "A cardiovascular simulator tailored for training and clinical uses," J Biomed Inform, vol. 57, pp. 100-112, Oct 2015 .

[20] M. Abdolrazaghi, M. Navidbakhsh, and K. Hassani, "Mathematical modelling and electrical analog equivalent of the human cardiovascular system," Cardiovascular Engineering, vol. 10, no. 2, pp. 45-51, 2010.

[21] D. Burkhoff and J. V. Tyberg, "Why does pulmonary venous pressure rise after onset of lv dysfunction: a theoretical analysis," American Journal of Physiology-Heart and Circulatory Physiology, vol. 265, no. 5, pp. H1819H1828, 1993.

[22] D. C. Chung, "Ventricular interaction in a closed-loop model of the canine circulation," Master's thesis, Rice University, Houston, Texas, 1996.

[23] M. Danielsen and J. T. Ottesen, "Describing the pumping heart as a pressure source," Journal of Theoretical Biology, vol. 212, no. 1, pp. $71-81$, 2001.

[24] L. M. Ellwein, H. T. Tran, C. Zapata, V. Novak, and M. S. Olufsen, "Sensitivity analysis and model assessment: Mathematical models for arterial blood flow and blood pressure," Cardiovascular Engineering, vol. 8, no. 2, pp. $94-108,2008$.

[25] S. R. Pope, L. M. Ellwein, C. L. Zapata, V. Novak, C. T. Kelley, and M. S. Olufsen, "Estimation and identification of parameters in a lumped cerebrovascular model," Math Biosci Eng, vol. 6, pp. 93-115, 2009.

[26] A. Pironet, T. Desaive, P. C. Dauby, J. G. Chase, and P. D. Docherty, "Parameter identification methods in a model of the cardiovascular system," in Preprints of the 9th IFAC Symposium on Biological and Medical Systems, pp. 366-371, 2015.

[27] C. Starfinger, C. Hann, J. Chase, T. Desaive, A. Ghuysen, and G. Shaw, "Model-based cardiac diagnosis of pulmonary embolism," Comput Methods Programs Biomed., 2007.

[28] J. T. Ottesen, V. Novak, and M. S. Olufsen, "Development of patient specific cardiovascular models predicting dynamics in response to orthostatic stress challenges," in Mathematical Modeling and Validation in Physiology, pp. 177-213, Springer, 2013. 
[29] J. A. Revie, D. J. Stevenson, J. G. Chase, C. E. Hann, B. C. Lambermont, A. Ghuysen, P. Kolh, G. M. Shaw, S. Heldmann, and T. Desaive, "Validation of subject-specific cardiovascular system models from porcine measurements," Computer Methods and Programs in Biomedicine, 2011b.

[30] C. Starfinger, J. G. Chase, C. E. Hann, G. M. Shaw, P. Lambert, B. W. Smith, E. Sloth, A. Larsson, S. Andreassen, and S. Rees, "Prediction of hemodynamic changes towards PEEP titrations at different volemic levels using a minimal cardiovascular model," Comput Methods Programs Biomed, vol. 91, pp. 128-134, Aug 2008.

[31] T. Parlikar and G. Verghese, "A simple cycle-averaged model for cardiovascular dynamics," Conf Proc IEEE Eng Med Biol Soc, vol. 5, pp. 5490-5494, 2005 .

[32] D. Rschen, M. Rimke, J. Gesenhues, S. Leonhardt, and M. Walter, "Continuous cardiac output estimation under left ventricular assistance," IFACPapersOnLine, vol. 48, no. 20, pp. 569 - 574, 2015. 9th IFAC Symposium on Biological and Medical Systems BMS 2015.

[33] M. S. Olufsen, J. T. Ottesen, H. T. Tran, L. M. Ellwein, L. A. Lipsitz, and V. Novak, "Blood pressure and blood flow variation during postural change from sitting to standing: model development and validation," $J$. Appl. Physiol., vol. 99, pp. 1523-1537, Oct 2005.

[34] L. Fresiello, G. Ferrari, A. Di Molfetta, K. Zieli?ski, A. Tzallas, S. Jacobs, M. Darowski, M. Kozarski, B. Meyns, N. S. Katertsidis, E. C. Karvounis, M. G. Tsipouras, and M. G. Trivella, "A cardiovascular simulator tailored for training and clinical uses," J Biomed Inform, vol. 57, pp. 100-12, 2015.

[35] M. L. Mogensen, A physiological mathematical model of the respiratory system. PhD thesis, Aalborg University, 2011.

[36] C. Schranz, C. Knobel, J. Kretschmer, Z. Zhao, and K. Moller, "Hierarchical parameter identification in models of respiratory mechanics," IEEE Trans Biomed Eng, vol. 58, pp. 3234-3241, Nov 2011.

[37] Y. S. Chiew, C. G. Pretty, P. D. Docherty, B. Lambermont, G. M. Shaw, T. Desaive, and J. G. Chase, "Time-varying respiratory system elastance: A physiological model for patients who are spontaneously breathing," PLOS One, January 2015.

[38] Y. S. Chiew, J. G. Chase, G. M. Shaw, A. Sundaresan, and T. Desaive, "Model-based peep otpimisation in mechanical ventilation," BioMedical Engineering OnLine, vol. 10, p. 111, 2011.

[39] K. Burrowes, A. Burrowes, N. Swan, M. Warren, and M. Tawhai, "Towards a virtual lung: Multi-scale, multi-physics modelling of the pulmonary system," Philosophical Transactions of the Royal Society A: Mathematical, 
Physical and Engineering Sciences, vol. Vol.366(1879), pp. pp.3247-3263, 28 September 2008.

[40] C. Schranz, P. D. Docherty, Y. S. Chiew, J. G. Chase, and K. Moller, "Structural identifiability and practical applicability of an alveolar recruitment model for ARDS patients," IEEE Trans Biomed Eng, vol. 59, pp. 3396-3404, Dec 2012.

[41] Y. S. Chiew, C. G. Pretty, G. M. Shaw, Y. W. Chiew, B. Lambermont, T. Desaive, and J. G. Chase, "Feasibility of titrating peep to minimum elastance for mechanically ventilated patients," Pilot and Feasibility Studies, 2015.

[42] J. G. Chase, A. J. Le Compte, J. C. Preiser, G. M. Shaw, S. Penning, and T. Desaive, "Physiological modeling, tight glycemic control, and the ICU clinician: what are models and how can they affect practice?," Ann Intensive Care, vol. 1, p. 11, May 2011.

[43] P. D. Docherty, J. G. Chase, T. F. Lotz, and T. Desaive, "A graphical method for practical and informative identifiability analyses of physiological models: a case study of insulin kinetics and sensitivity," Biomedical Engineering Online, vol. 10, p. 39, 2011.

[44] S. M. Davidson, D. O. Kannangara, C. G. Pretty, S. Kamoi, A. Pironet, D. T., and J. G. Chase, "Modelling of the nonlinear end-systolic pressurevolume relation and volume-at-zero-pressure in porcine experiments," in Conf Proc IEEE Eng Med Biol Soc, August 2015.

[45] A. Sundaresan, J. G. Chase, G. M. Shaw, Y. S. Chiew, and T. Desaive, "Model-based optimal peep in mechanically ventilated ards patients in the intensive care unit," BioMedical Engineering OnLine, 2011.

[46] A. Sundaresan and J. G. Chase, "Positive end expiratory pressure in patients with acute respiratory distress syndrome the past, present and future," Biomedical Signal Processing and Control, vol. 7, no. 93-103, 2012.

[47] J. Choi, G. Xia, M. H. Tawhai, E. A. Hoffman, and C.-L. Lin, "Numerical study of high-frequency oscillatory air flow and convective mixing in a ctbased human airway model," Annals of biomedical engineering, vol. 38, no. 12 , pp. $3550-3571,2010$.

[48] E. J. van Drunen, Y. S. Chiew, C. J. G., G. M. Shaw, B. Lambermont, N. Janssen, N. S. Damanhuri, and T. Desaive, "Expiratory model-based method to monitor ards disease state," BioMedical Engineering OnLine, p. 12:57, June 2013.

[49] T. Luecke and P. Pelosi, "Clinical review: Positive end-expiratory pressure and cardiac output," Critical Care, vol. Vol.9(6), no. p.607-621, 2005. 
[50] D. A. Kass, W. L. Maughan, Z. M. Guo, A. Kono, K. Sunagawa, and K. Sagawa, "Comparative influence of load versus inotropic states on indexes of ventricular contractility: experimental and theoretical analysis based on pressure-volume relationships.," Circulation, vol. 76, no. 6, pp. 1422-1436, 1987.

[51] J. A. Nelder and R. Mead, "A simplex method for function minimization," The Computer Journal, vol. 7, no. 4, pp. 308-313, 1965.

[52] D. A. Kass, R. Beyar, E. Lankford, M. Heard, W. L. Maughan, and K. Sagawa, "Influence of contractile state on curvilinearity of in situ endsystolic pressure-volume relations," Circulation, vol. 79, no. 1, pp. 167-178, 1989.

[53] R. Klabunde and A. Dalley, Cardiovascular physiology concepts. Lippincott Williams \& Wilkins, 2004.

[54] F. Michard, "Changes in arterial pressure during mechanical ventilation," Anesthesiology, vol. 103, no. 2, pp. 419-428, 2005.

[55] B. Laufer, P. Docherty, A. Knörzer, Y. Chiew, R. Langdon, K. Möller, and J. Chase, "Performance of variations of the dynamic elastance model in lung mechanics," Control Engineering Practice, pp. -, 2016. In press.

[56] N. Westerhof, N. Stergiopulos, and M. I. M. Noble, Snapshots of Hemodynamics. Springer, 2010. 


\section{Appendix A. Choice of signals used for model fitting}

The components of the model output vector $\mathbf{y}(\mathbf{p})$ were the following (calculated over $N=20$ simulated cardiac periods):

- $\bar{P}_{a o}$ and $\Delta P_{a o}$, computed on the model output $P_{a o}(t)+P_{t h}(t)$. The model was built with the aortic chamber out of the thoracic cavity. However, the aortic catheter measurement was performed in the proximal aorta, which is located inside the thoracic cavity. Therefore, it was chosen that the modelled output $P_{a o}(t)+P_{t h}(t)$ should be compared to the measured signal $P_{a o, m}(t)$ for the parameter estimation.

- $\bar{P}_{v c}$ and $\Delta P_{v c}$, computed on the model output $P_{v c}(t)-P_{t h}(t)$. A similar difference between the model compartments and the measurement location was observed for the venous pressure, but the other way around. In the model, the venous compartment was considered inside the thoracic cavity, while the measurement was performed in the superior vena cava, which does not experience thoracic pressure. Therefore, the model output $P_{v c}(t)-P_{t h}(t)$ was compared to the measured $P_{v c, \max }$ and $P_{v c, \text { min }}$ of the PiCCO for the parameter estimation.

- $\bar{V}_{l v}$ and $\Delta V_{l v}$, computed on $V_{l v}(t)$ from the simulation.

- $\Delta P_{a o, \max }$ computed as explained above from the model output $P_{a o}(t)+$ $P_{t h}(t)$. 


\section{Appendix B. Left ventricle Pressure-Volume loops}

Figure B.10 compares the pressure-volume loops of the left ventricles during the preload reduction experiments performed on all datasets (all three pigs, at every PEEP level).
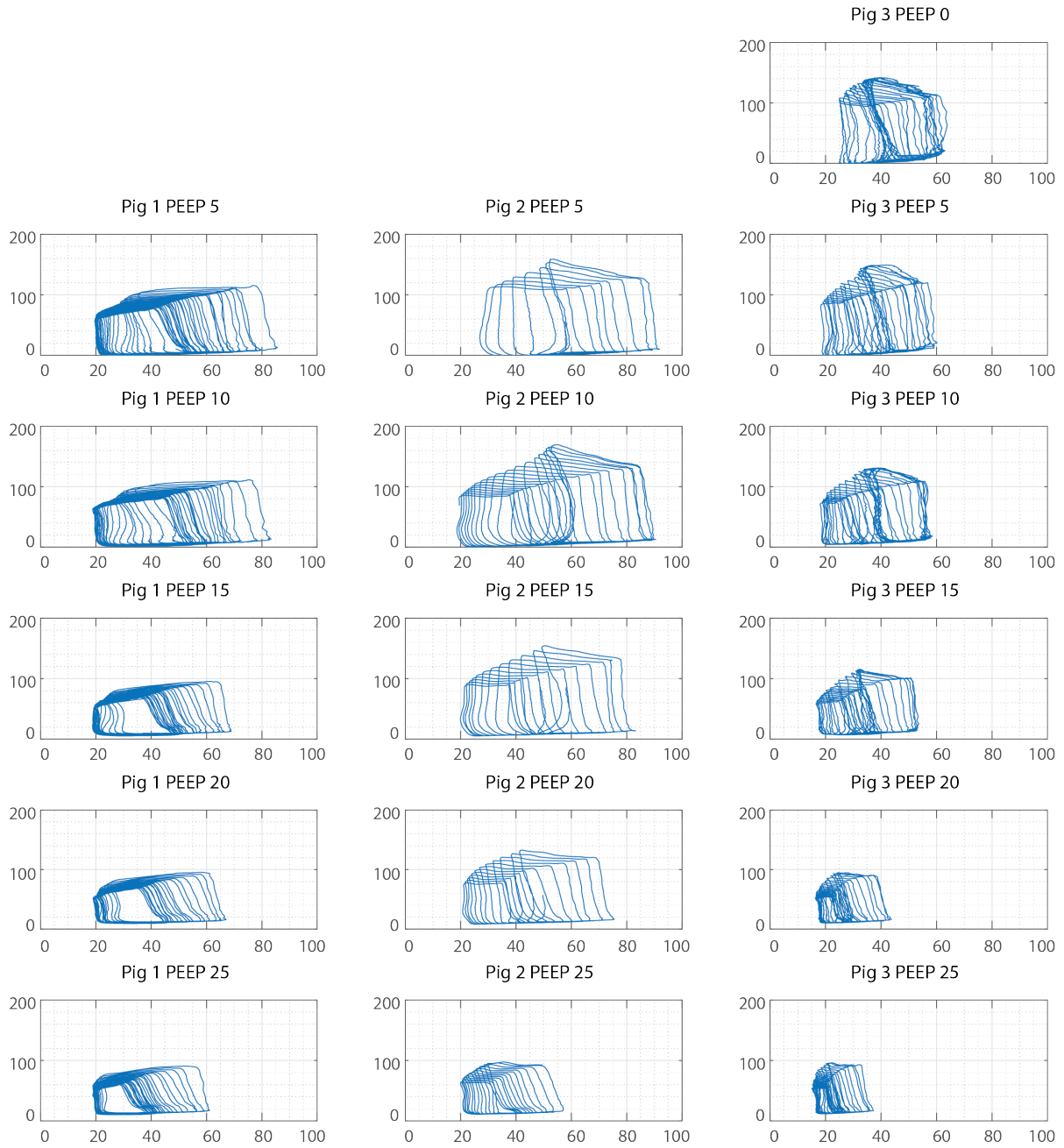

Figure B.10: Measured left ventricular pressure-volume loops for all datasets (all three pigs, at every PEEP level) during the first preload reduction experiment performed at each PEEP level. The volumes are shown in $\mathrm{ml}$ and the pressures in $\mathrm{mmHg}$. 


\section{Appendix C. Relative fitting errors}

Table C.5 shows the fitting errors obtained after iterative parameter estimation for all the datasets (every pig, at every PEEP level). The columns are the components of the error vector e (cf. Equation 25), calculated with the optimal parameter values and the reference values (cf. Table 1 and Appendix D), the rows represent the several datasets of this study.

\begin{tabular}{l|rrrrrrr} 
& $e_{1}$ & $e_{2}$ & $e_{3}$ & $e_{4}$ & $e_{5}$ & $e_{6}$ & $e_{7}$ \\
\hline Pig 1 & & & & & & & \\
PEEP 5 & 0.0076 & 0.0285 & -0.1841 & 0.0433 & -0.0128 & -0.1015 & 0.0001 \\
PEEP 10 & -0.0027 & 0.0007 & -0.0055 & -0.0006 & 0.0424 & -0.0325 & -0.0006 \\
PEEP 15 & -0.0001 & -0.0012 & -0.0068 & -0.0035 & 0.1373 & 0.0105 & -0.0003 \\
PEEP 20 & -0.0991 & 0.0022 & -0.0064 & 0.0497 & 0.0113 & -0.4529 & 0.0002 \\
PEEP 25 & -0.1044 & 0.5642 & -0.0117 & 0.0034 & -0.0011 & -0.2941 & 0.0000 \\
\hline Pig 2 & & & & & & & \\
PEEP 5 & -0.0004 & -0.0023 & -0.0006 & 0.0050 & -0.0345 & -0.0022 & 0.0011 \\
PEEP 10 & -0.0029 & 0.0214 & -0.0003 & 0.0059 & -0.0058 & -0.1223 & -0.0021 \\
PEEP 15 & -0.0046 & -0.0026 & 0.0030 & -0.0003 & 0.1400 & -0.5292 & 0.0035 \\
PEEP 20 & -0.8455 & 0.0002 & -0.0373 & 0.0346 & 0.2617 & -0.1470 & 0.0082 \\
PEEP 25 & -0.4681 & 0.0011 & -0.0016 & 0.0012 & 0.1846 & -0.1465 & 0.2998 \\
\hline Pig 3 & & & & & & & \\
PEEP 0 & 0.0052 & 0.0010 & -0.1951 & 0.0028 & -0.0734 & -0.0933 & 0.0004 \\
PEEP 5 & -0.0028 & 0.0229 & -0.0926 & 0.0205 & -0.1912 & -0.6373 & -0.0074 \\
PEEP 10 & -0.0041 & 0.0066 & -0.0019 & 0.0129 & -0.2173 & -0.9550 & -0.0034 \\
PEEP 15 & -0.0007 & 0.0057 & -0.0072 & 0.0965 & -0.0082 & -0.8261 & -0.0035 \\
PEEP 20 & -0.5682 & 0.1419 & 0.2080 & 0.0200 & -0.0223 & -0.8401 & -0.0024 \\
PEEP 25 & -0.0133 & 0.1031 & 0.0279 & 0.0184 & 0.0292 & -1.0228 & 0.0615
\end{tabular}

Table C.5: Relative error vectors e obtained on the pigs after iterative estimation of the parameters on the different datasets. PEEP levels are given in $\mathrm{cm}_{2} \mathrm{O}$ 


\section{Appendix D. Reference values}

Table D.6 shows all the reference values of the reference vector $\mathbf{y}^{\text {ref }}$, for all the datasets (every pig, at every PEEP level).

\begin{tabular}{l|l|rrrrrr}
\multicolumn{2}{c}{ Output } & PEEP & PEEP & PEEP & PEEP & PEEP & PEEP \\
\cline { 2 - 7 } & & 0 & 5 & 10 & 15 & 20 & 25 \\
\hline $\bar{P}_{a o, m}$ & Pig 1 & N/A & 98.666 & 88.436 & 74.743 & 71.44 & 67.763 \\
& Pig 2 & N/A & 147.942 & 151.646 & 144.478 & 124.278 & 87.624 \\
& Pig 3 & 128.009 & 122.679 & 114.898 & 96.671 & 81.481 & 89.529 \\
\hline$\Delta P_{a o, m}$ & Pig 1 & N/A & 35.804 & 37.083 & 36.124 & 35.272 & 33.034 \\
$m m H g$ & Pig 2 & N/A & 46.261 & 45.515 & 37.308 & 32.298 & 22.997 \\
& Pig 3 & 41.998 & 43.916 & 43.703 & 38.16 & 27.821 & 26.222 \\
\hline $\bar{P}_{v c, m}$ & Pig 1 & N/A & 11 & 12.5 & 14 & 15.5 & 17 \\
$m m H g$ & Pig 2 & N/A & 11 & 13.5 & 16 & 17 & 19.5 \\
& Pig 3 & 11.833 & 11.5 & 12 & 14.5 & 15 & 18 \\
\hline$\Delta P_{v c, m}$ & Pig 1 & N/A & 10 & 9 & 10 & 11 & 12 \\
$m m H g$ & Pig 2 & N/A & 10 & 9 & 8 & 6 & 7 \\
& Pig 3 & 3.667 & 5 & 4 & 5 & 6 & 6 \\
\hline $\bar{V}_{l v, m}$ & Pig 1 & N/A & 68.342 & 63.133 & 51.354 & 45.06 & 40.552 \\
$m l$ & Pig 2 & N/A & 73.179 & 72.483 & 68.475 & 60.305 & 42.656 \\
& Pig 3 & 49.556 & 49.1 & 47.229 & 41.637 & 33.077 & 28.89 \\
\hline$\Delta V_{l v, m}$ & Pig 1 & N/A & 44.285 & 45.719 & 48.606 & 43.96 & 39.801 \\
$m l$ & Pig 2 & N/A & 42.35 & 39.07 & 36.473 & 35.053 & 28.616 \\
& Pig 3 & 25.098 & 23.708 & 20.378 & 22.205 & 18.756 & 16.863 \\
\hline$\Delta P_{a o, m, m a x}$ & Pig 1 & N/A & 4.689 & 4.902 & 4.476 & 3.73 & 5.861 \\
$m m H g$ & Pig 2 & N/A & 6.396 & 6.236 & 9.007 & 6.289 & 6.369 \\
& Pig 3 & 3.091 & 4.69 & 4.69 & 7.462 & 8.208 & 12.045
\end{tabular}

Table D.6: Reference values composing the vector $\mathbf{y}^{\text {ref }}$ calculated on all the different datasets, for every pig at every PEEP level. PEEP levels are given in $\mathrm{cm}_{2} \mathrm{O}$. 


\section{Appendix E. Parameter estimations results}

Table E.7 shows all estimated parameter values, resulting from the direct and iterative estimations (cf. Section 2.7) for all the datasets (every pig, at every PEEP level).

\begin{tabular}{|c|c|c|c|c|c|c|c|}
\hline \multicolumn{2}{|c|}{ Parameter } & \multirow{2}{*}{$\begin{array}{r}\text { PEEP } \\
0 \\
\mathrm{~N} / \mathrm{A}\end{array}$} & $\begin{array}{r}\text { PEEP } \\
5 \\
\end{array}$ & \multirow{2}{*}{$\begin{array}{r}\text { PEEP } \\
10 \\
2.147\end{array}$} & \multirow{2}{*}{$\begin{array}{r}\text { PEEP } \\
15 \\
4.366\end{array}$} & \multirow{2}{*}{$\begin{array}{r}\text { PEEP } \\
20 \\
6.227\end{array}$} & \multirow{2}{*}{$\begin{array}{r}\text { PEEP } \\
25 \\
9.98\end{array}$} \\
\hline$E_{l v, e s}$ & Pig 1 & & 2.261 & & & & \\
\hline \multirow[t]{2}{*}{$m m H g / m l$} & Pig 2 & $\mathrm{~N} / \mathrm{A}$ & 2.118 & 2.262 & 2.074 & 2.289 & 2.952 \\
\hline & Pig 3 & 2.809 & 3.15 & 2.788 & 3.248 & 4.683 & 7.079 \\
\hline \multirow{3}{*}{$\begin{array}{l}E_{l v, e d} \\
m m H g / m l\end{array}$} & Pig 1 & $\mathrm{~N} / \mathrm{A}$ & 0.001 & 0.053 & 0.174 & 0.114 & 0.14 \\
\hline & Pig 2 & $\mathrm{~N} / \mathrm{A}$ & 0.16 & 0.145 & 0.121 & 0.171 & 0.241 \\
\hline & Pig 3 & 0.001 & 0.003 & 0.085 & 0.185 & 0.137 & 0.228 \\
\hline \multirow{3}{*}{$\begin{array}{l}E_{a o} \\
m m H g / m l\end{array}$} & Pig 1 & $\mathrm{~N} / \mathrm{A}$ & 1.025 & 1.17 & 1.187 & 13.206 & 3.374 \\
\hline & Pig 2 & $\mathrm{~N} / \mathrm{A}$ & 1.403 & 1.324 & 0.896 & 1.07 & 1.003 \\
\hline & Pig 3 & 2.117 & 1.559 & 1.517 & 1.387 & 1.004 & 3.9 \\
\hline \multirow{3}{*}{$\begin{array}{l}E_{v c} \\
m m H g / m l\end{array}$} & Pig 1 & $\mathrm{~N} / \mathrm{A}$ & 0.226 & 0.224 & 0.274 & 0.166 & 0.25 \\
\hline & Pig 2 & $\mathrm{~N} / \mathrm{A}$ & 0.301 & 0.258 & 0.189 & 0.204 & 0.313 \\
\hline & Pig 3 & 0.143 & 0.138 & 0.112 & 0.139 & 0.232 & 0.181 \\
\hline \multirow{3}{*}{$\begin{array}{l}E_{\text {wall }} \\
m m H g / m l\end{array}$} & Pig 1 & $\mathrm{~N} / \mathrm{A}$ & 0.011 & 0.011 & 0.012 & 0.007 & 0.014 \\
\hline & Pig 2 & $\mathrm{~N} / \mathrm{A}$ & 0.017 & 0.018 & 0.024 & 0.015 & 0.011 \\
\hline & Pig 3 & 0.005 & 0.013 & 0.013 & 0.02 & 0.024 & 0.025 \\
\hline \multirow{3}{*}{$\begin{array}{l}E_{r s} \\
m m H g / m l\end{array}$} & Pig 1 & $\mathrm{~N} / \mathrm{A}$ & 0.029 & 0.02 & 0.01 & 0.004 & 0.009 \\
\hline & Pig 2 & $\mathrm{~N} / \mathrm{A}$ & 0.025 & 0.018 & 0.01 & 0.003 & 0.005 \\
\hline & Pig 3 & 0.057 & 0.038 & 0.023 & 0.012 & 0.008 & 0.014 \\
\hline \multirow{3}{*}{$\begin{array}{l}R_{s y s} \\
m m H g \cdot s / m l\end{array}$} & Pig 1 & $\mathrm{~N} / \mathrm{A}$ & 0.769 & 0.699 & 0.391 & 0.05 & 0.009 \\
\hline & Pig 2 & $\mathrm{~N} / \mathrm{A}$ & 2.716 & 2.357 & 1.166 & 1.184 & 0.607 \\
\hline & Pig 3 & 2.603 & 1.806 & 1.689 & 0.784 & 0.553 & 0.083 \\
\hline \multirow{3}{*}{$\begin{array}{l}R_{a o v} \\
m m H g \cdot s / m l\end{array}$} & Pig 1 & $\mathrm{~N} / \mathrm{A}$ & 0.04 & 0.04 & 0.04 & 0.04 & 0.04 \\
\hline & Pig 2 & $\mathrm{~N} / \mathrm{A}$ & 0.04 & 0.04 & 0.04 & 0.04 & 0.04 \\
\hline & Pig 3 & 0.04 & 0.04 & 0.04 & 0.04 & 0.04 & 0.04 \\
\hline \multirow{3}{*}{$\begin{array}{l}R_{m i t} \\
m m H g \cdot s / m l\end{array}$} & Pig 1 & $\mathrm{~N} / \mathrm{A}$ & 0.001 & 0.001 & 0.001 & 0.001 & 0.001 \\
\hline & Pig 2 & $\mathrm{~N} / \mathrm{A}$ & 0.001 & 0.001 & 0.001 & 0.001 & 0.001 \\
\hline & Pig 3 & 0.001 & 0.001 & 0.001 & 0.001 & 0.001 & 0.001 \\
\hline \multirow{3}{*}{$\begin{array}{l}W \\
s^{-2}\end{array}$} & Pig 1 & $\mathrm{~N} / \mathrm{A}$ & 62.433 & 59.97 & 75.546 & 96.239 & 116.312 \\
\hline & Pig 2 & $\mathrm{~N} / \mathrm{A}$ & 34.58 & 35.009 & 35.481 & 38.897 & 51.168 \\
\hline & Pig 3 & 30.068 & 31.264 & 30.926 & 42.49 & 62.23 & 82.361 \\
\hline \multirow{3}{*}{$\begin{array}{l}T_{\text {heart }} \\
s\end{array}$} & Pig 1 & $\mathrm{~N} / \mathrm{A}$ & 0.465 & 0.491 & 0.549 & 0.566 & 0.57 \\
\hline & Pig 2 & $\mathrm{~N} / \mathrm{A}$ & 0.884 & 0.847 & 0.867 & 0.958 & 0.789 \\
\hline & Pig 3 & 0.627 & 0.653 & 0.712 & 0.74 & 0.677 & 0.618 \\
\hline \multirow{3}{*}{$\begin{array}{l}V_{l v, d} \\
" m l "\end{array}$} & Pig 1 & $\mathrm{~N} / \mathrm{A}$ & -4.468 & -9.244 & 5.576 & 9.136 & 12.515 \\
\hline & Pig 2 & $\mathrm{~N} / \mathrm{A}$ & -24.224 & -19.493 & -22.453 & -12.306 & -0.544 \\
\hline & Pig 3 & -13.32 & -5.612 & -8.074 & -1.767 & 5.678 & 7.783 \\
\hline \multirow{3}{*}{$\begin{array}{l}V_{l v, u} \\
m l\end{array}$} & Pig 1 & $\mathrm{~N} / \mathrm{A}$ & 44.052 & 41.532 & 21.574 & -12.168 & -13.208 \\
\hline & Pig 2 & $\mathrm{~N} / \mathrm{A}$ & 61.046 & 35.982 & -9.532 & -23.111 & -16.171 \\
\hline & Pig 3 & 44.263 & 32.081 & 17.175 & -0.773 & -12.736 & -18.377 \\
\hline
\end{tabular}

Table E.7: Estimated model parameters on all the different datasets, for every pig at every PEEP level. PEEP levels are given in $\mathrm{cmH}_{2} \mathrm{O}$. 